\title{
KANT E HOBBES: COERÊNCIA E INCOERÊNCIA OBRIGACIONAL EM FACE DE UM ESTADO TIRÂNICO OU INJUSTO
}

Kant and Hobbes: binding coherence and incoherence before a tyrannical or unjust state

Delamar José Volpato Dutra *

Resumo: o texto apresenta o conceito de obrigação em Hobbes e em Kant. Argumenta-se que Kant não foi capaz de manter a coerência de seu conceito de obrigação quando tratou da sua aplicação ao caso extremo do jus necessitatis, pois teve que distinguir entre punibilidade e culpabilidade. Hobbes, por seu turno, pôde manter a coerência de seu conceito de obrigação mesmo para este caso.

Palavras-chave: Obrigação política. Jus necessitatis. Hobbes. Kant.

Abstract: The text presents the concept of obligation in Hobbes and Kant. It is argued that Kant was not able to maintain the coherence of his concept of obligation when he dealt with its application to the extreme case of jus necessitatis, since he had to distinguish between punishment and guilt [for one is not to be judged inculpable (inculpabile) but only unpunishable (impunibile)]. Hobbes, for his part, was able to maintain the coherence of his concept of obligation even in this case.

Keywords: Political obligation. Jus necessitatis. Hobbes. Kant.

* Doutor em Filosofia. Professor da Universidade Federal de Santa Catarina (UFSC). Pesquisa apoiada pelo CNPq. Artigo recebido em 31/05/2019 e aprovado para publicação em 30/01/2020. 


\section{Introdução}

$\mathrm{U}$

T dos pomos de discórdia entre Hobbes e Kant, especificamente em relação ao texto Contra Hobbe ${ }^{1}$, é aquele referente ao conceito de obrigação. Kant sustenta uma obrigação incondicional ancorada em uma determinação a priori da razão. Hobbes, por seu turno, muito embora conceda que a lei natural vincule interiormente, para ele, o conceito de obrigação que realmente importa é aquele fundamentado no contrato, cuja base, como se sabe, reside na autopreservação, obrigação esta que Kant não tem dúvidas em classificá-la como hipotética, pois justamente dependente de um fim que se deve pressupor. E essa discordância que parece estar em questão justamente no primeiro parágrafo do texto Contra Hobbes. Com efeito, nele Kant afirma que o contrato social se distingue de todo outro contrato por ser um fim em si mesmo. Ora, uma finalidade em si mesma que é ditada pela razão fundamentaria uma obrigação incondicional.

O presente estudo pretende sustentar duas hipóteses. A primeira delas diz respeito aos conteúdos, à substância dos direitos básicos, em Kant, e da lei natural em Hobbes. Sustenta-se que a fundamentação estratégica das leis naturais por Hobbes não desqualifica o conteúdo das mesmas como sendo de estirpe moral. Sustenta-se uma equivalência entre os conteúdos da lei natural em Hobbes e os conteúdos ditados pelo princípio universal do direito formulado por Kant, mormente no que diz respeito à liberdade, à igualdade e ao cumprimento dos pactos.

A segunda hipótese diz respeito à coerência de ambos os pensadores com seus respectivos fundamentos obrigacionais. Nesse particular, defende-se que Hobbes é mais coerente do que Kant, ao menos no que diz respeito à liberdade do súdito frente a um Estado injusto, haja vista este negar um direito no estado de necessidade nesse domínio e aquele não só aceitar o direito no estado de necessidade como admitir a perfeita compatibilidade de ambos os conceitos.

\section{Da obrigação em Hobbes}

Warrender defendeu a tese de que a obrigação em Hobbes se fundamentaria em um mandamento de Deus. A sua tese é a de que a lei natural não teria sentido obrigacional se ela não fosse um comando

\footnotetext{
${ }^{1}$ Contra Hobbes foi um dos subtítulos que Kant deu à segunda parte do seu texto Sobre a expressão corrente: isso pode ser correto na teoria, mas nada vale na prática. Ao longo deste artigo ele será designado como Contra Hobbes, algo comum na literatura kantiana. As referências a Kant, incluso no que diz respeito às abreviaturas, seguem a uniformização proposta pela Kant-Studien Redaktion, disponíveis em http://www.kant.uni-mainz.de/ks/abhandlungen.html As citações literais são feitas a partir das traduções para o vernáculo das referidas obras.
} 
divino. ${ }^{2}$ Taylor vislumbrou nas declarações de Hobbes, especialmente na distinção do De cive entre um homem justo e uma ação justa, algo equivalente ao imperativo categórico. ${ }^{3}$ Tais interpretações são problemáticas, pois parecem não honrar o caráter contratual das obrigações em Hobbes: "[...] ninguém tem qualquer obrigação que não derive de algum de seus próprios atos"4. Como em qualquer contrato, há uma renúncia de direitos, a qual cria obrigações, o que significa dizer que vínculos são estabelecidos na proporção direta da renúncia a direitos naturais:

Quando de qualquer destas maneiras alguém abandonou ou adjudicou seu direito, diz-se que fica obrigado ou forçado a não impedir àqueles a quem esse direito foi abandonado ou adjudicado o respectivo benefício, e que deve, e é seu dever, não tornar nulo esse seu próprio ato voluntário; e que tal impedimento é injustiça e injúria, dado que é sine jure, pois se transferiu ou se renunciou ao direito. ${ }^{5}$

Segundo as palavras do comentador, "Hobbes define 'obrigação' como abandonar ou conceder um direito (por exemplo, em um contrato)." ${ }^{\prime 6}$

Quiçá, o ponto mais importante para esclarecer a fundamentação das leis naturais em Hobbes, bem como para esclarece a fundamentação do caráter obrigacional dos contratos, seja o seu argumento contra o louco ou contra o tolo [foole]. O argumento do tolo consiste em defender, sob o ponto de vista do interesse próprio, a racionalidade do cumprimento da sua parte do contrato, quando o outro já cumpriu a sua. Hobbes alega que não é racional deixar de cumpri-lo, pois, o possível benefício resultante do seu descumprimento, por mais garantido que fosse, só ocorreria por acidente, de tal forma que não poderia ser razoavelmente e sabiamente escolhida tal opção:

Para prová-lo, há várias coisas a considerar. Em primeiro lugar, quando alguém pratica uma ação que, na medida em que é possível prever e calcular, tende para sua própria destruição, mesmo que algum acidente inesperado venha a torná-la benéfica para ele, tais acontecimentos não a transformam numa ação razoável ou judiciosa. ${ }^{7}$

\footnotetext{
${ }^{2}$ WARRENDER, Howard. The Political Philosophy of Hobbes. Oxford: Oxford University Press, 1957, p. 322.

${ }^{3}$ TAYLOR, Alfred Edward. The Ethical Doctrine of Hobbes. Philosophy. N. 13, 1938, p. 406-424.

${ }^{4}$ HOBBES, Thomas. Leviatã ou matéria, forma e poder de um estado eclesiástico e civil. [Trad. J. P. Monteiro e M.B.N. da Silva: Leviathan, or Matter, Form, and Power of a Commonwealth Ecclesiastical and Civil]. 2. ed., São Paulo: Abril Cultural, 1983 [1651], cap. XXI.

${ }^{5}$ HOBBES, Thomas. Leviatã ou matéria, forma e poder de um estado eclesiástico e civil. [Trad. J. P. Monteiro e M.B.N. da Silva: Leviathan, or Matter, Form, and Power of a Commonwealth Ecclesiastical and Civil]. 2. ed., São Paulo: Abril Cultural, 1983 [1651], cap. XIV.

${ }^{6}$ DARWALL, Stephen. The British Moralists and the Internal 'Ought': 1640-1740. Cambridge: Cambridge University Press, 1995, p. 54.

${ }^{7}$ HOBBES, Thomas. Leviatã ou matéria, forma e poder de um estado eclesiástico e civil. [Trad. J. P. Monteiro e M.B.N. da Silva: Leviathan, or Matter, Form, and Power of a Commonwealth Ecclesiastical and Civil]. 2. ed., São Paulo: Abril Cultural, 1983 [1651], cap. XV.
} 
Para Hobbes, o rompimento unilateral do contrato gera um tipo de desconfiança que implica a expulsão do faltoso de qualquer sociedade. $\mathrm{Ou}$ seja, para ele continuar a viver em sociedade, o que, aliás, é essencial para a sua sobrevivência, ele dependeria de os outros terem um juízo falso a seu respeito, ou seja, como sendo cumpridor dos contratos, o que ele na verdade não seria. Contudo, não é razoável ou sábio fazer a própria segurança depender de um erro de avaliação dos outros. ${ }^{8}$

Para Kavka, o argumento contra o louco mostra que o critério de racionalidade em Hobbes não é nem utilitarista e nem é uma análise caso a caso, mas é uma consideração da propriedade da regra de ser um meio de autoconservação. ${ }^{9} \mathrm{O}$ cerne do argumento, para ele, residiria na noção de incerteza. Nesse sentido, esclarece ele, seriam quatro os elementos que caracterizam a racionalidade baseada na incerteza defendida por Hobbes no argumento contra o louco.

Em primeiro lugar, o raciocínio seria sempre prospectivo [forward-looking], ou seja, o adimplemento de um contrato no presente seria sempre avaliado como um "[...] significa garantir cooperação futura e confiança de outras pessoas." 10

Em segundo lugar, as escolhas seriam feitas sob condição de incerteza, ou seja, os resultados que possivelmente adviriam das escolhas caso a caso não estariam disponíveis. ${ }^{11}$

Em terceiro lugar, o jogo "agir em segurança sob incerteza" seria diferente de um cálculo de utilidade caso a caso:

[...] é racional agir em segurança sob incerteza, evitando arriscar resultados muito ruins na esperança de obter ganhos incertos. Em particular, é irracional arriscar o ostracismo social, cometendo uma violação ofensiva de uma regra moral central (isto é, uma lei da natureza), na esperança de obter os

\footnotetext{
8 "He therefore that breaketh his Covenant, and consequently declareth that he thinks he may with reason do so, cannot be received into any Society, that unite themselves for Peace and Defence, but by the errour of them that receive him; nor when he is received, be retayned in it, without seeing the danger of their errour; which errours a man cannot reasonably reckon upon as the means of his security: and therefore if he be left, or cast out of Society, he perisheth; and if he live in Society, it is by the errours of other men, which he could not foresee, nor reckon upon; and consequently against the reason of his preservation; and so, as all men that contribute not to his destruction, forbear him onely out of ignorance of what is good for themselves." [HOBBES, Thomas. Leviathan, or Matter, Form, and Power of a Commonwealth Ecclesiastical and Civil. [Edited by C.B. Macpherson]. London: Penguin, 1968 [1651], chap. XV].

${ }^{9}$ KAVKA, Gregor. The Rationality of Rule-Following: Hobbes' Dispute with the Foole. Law and Philosophy. V. 14, 1995, p. 21.

${ }^{10}$ KAVKA, Gregor. The Rationality of Rule-Following: Hobbes' Dispute with the Foole. Law and Philosophy. V. 14, 1995, p. 21.

${ }^{11}$ KAVKA, Gregor. The Rationality of Rule-Following: Hobbes' Dispute with the Foole. Law and Philosophy. V. 14, 1995, p. 21.
} 
ganhos relativamente pequenos e incertos que possam resultar em não ser descoberto em tal violação. ${ }^{12}$

Portanto, o louco argumentaria a partir do benefício caso a caso e Hobbes responderia em termos de longo prazo.

Em quarto lugar, seguir regras rigidamente, a longo prazo, seria mais seguro para a autoconservação:

[...] o compromisso prévio (ou o cumprimento rígido de regras) é racional no seguinte sentido: é provável que se obtenha melhor desempenho geral seguindo rigidamente as regras morais fundamentais do que calculando riscos aceitáveis em ocasiões específicas, porque erros e preconceitos nesses cálculos tenderão a levar a assumir riscos excessivos em casos particulares. ${ }^{13}$

Em suma, "Como os benefícios da violação são incertos e os riscos de falha são tão graves, é racional, em termos puramente prospectivos, garantir a segurança e seguir a terceira (ou outra) lei da natureza geralmente benéfica." ${ }^{14}$ Darwall também argumenta nesse mesmo sentido da incerteza. ${ }^{15}$

Desse modo, o jogo "agir em segurança sob incerteza" explicaria não só por que é racional cumprir os contratos no estado civil, mas, também, por que é racional fazer a guerra no estado de natureza, pois tratar-se-ia de perspectivas de sobrevivência a longo prazo sob circunstâncias diferentes. Ora, no estado de natureza tal perspectiva de sobrevivência é quase zero, mesmo fazendo a guerra, ao passo que no estado civil é uma perspectiva alta. ${ }^{16}$ Decorre disso que o cumprimento dos contratos ditado pela terceira lei natural, incluso aí o contrato social, é posto como condição para a autoconservação e para a paz.

O argumento contra o louco mostra a conexão entre a lei natural, a autopreservação e a motivação. Ele mostra por que o louco avalia mal o que lhe é benéfico, talvez, devido à sua visão de curto prazo. Em última análise, o argumento que opera é aquele da quebra da confiança, aliás, o

${ }^{12}$ KAVKA, Gregor. The Rationality of Rule-Following: Hobbes' Dispute with the Foole. Law and Philosophy. V. 14, 1995, p. 21-22.

${ }^{13}$ KAVKA, Gregor. The Rationality of Rule-Following: Hobbes' Dispute with the Foole. Law and Philosophy. V. 14, 1995, p. 21-22.

${ }^{14}$ KAVKA, Gregor. The Rationality of Rule-Following: Hobbes' Dispute with the Foole. Law and Philosophy. V. 14, 1995, p. 23.

15 "To put the point in today's decision- theoretic terms, Hobbes's position appears to be that when it comes to keeping or breaking covenant, rational deliberators will treat the problem not as a decision under conditions of risk, where they attempt to estimate and take account of the likelihood of various outcomes, but as one of uncertainty, where they cannot rationally take such estimates into account." [DARWALL, Stephen. The British Moralists and the Internal 'Ought': 1640-1740. Cambridge: Cambridge University Press, 1995, p. 76].

${ }^{16}$ KAVKA, Gregor. The Rationality of Rule-Following: Hobbes' Dispute with the Foole. Law and Philosophy. V. 14, 1995, p. 23. 
mesmo que opera na primeira fórmula do imperativo categórico a respeito da falsa promessa, justamente o único dever cujo descumprimento gera um tipo de autocontradição, ou seja, gera uma impossibilidade interna. Pergunta-se, qual é mesmo o sentido dessa alegada impossibilidade interna que gera uma contradição? Nada mais do que a quebra da confiança, a qual "tornaria impossível o próprio prometer e o fim que se pode ter com isso, porque ninguém acreditaria que algo teria sido prometido a ele, mas rir-se-ia de todo proferimento semelhante como uma vã alegação"17. Ora, é justamente a quebra da confiança que gera a expulsão do faltoso e o condena ao estado de natureza, um estado miserável de guerra, em que a chance de sobrevivência é praticamente zero. Como bem anota Hobbes "[...] é a fé, somente, o que nos prende nos contratos."18

Frente aos cálculos da razão, o louco não pode simplesmente desejar continuar no estado de natureza, pois isto estaria em contradição com a sua própria autopreservação ${ }^{19}$. É de se mencionar, por oportuno, a relação do argumento contra o louco com o conceito de obrigação. É o que, por exemplo, faz Rawls. De fato, após a análise do argumento, Rawls conclui que, nele, Hobbes não apela à noção de obrigação moral ${ }^{20}$. Veja-se, no entanto, que ele observa se tratar da obrigação moral "como normalmente é entendida". Ato contínuo, ele explica, então, como ela é normalmente entendida. Segundo Rawls, para que haja uma obrigação moral duas condições devem ser cumpridas.

De acordo com a primeira condição, uma obrigação, como normalmente é entendida, ao menos como Rawls pensa que ela é normalmente entendida, deveria valer mesmo que o seu cumprimento envolvesse uma perda total para o que a cumprisse, ou seja, ainda que ele não tivesse nenhuma vantagem, mesmo que de longo prazo $^{21}$. Essa análise da obrigação é, sem dúvida, de estirpe kantiana. Mesmo um autor como Hart a formula em termos semelhantes. De acordo com ele, uma obrigação pode decorrer de

\footnotetext{
${ }^{17}$ KANT, Immanuel. Fundamentação da metafísica dos costumes. [Trad. G. A. de Almeida: Grundlegung zur Metaphysik der Sitten]. São Paulo: Discurso Editorial/Barcarolla, 2009 [1785], p. 422 [GMS, AA 04: 422].

${ }^{18}$ HOBBES, Thomas. Do cidadão. [R. J. Ribeiro: Philosophical Rudiments Concerning Government and Society]. 2. ed., São Paulo: Martins Fontes, 1998 [1642], p. 107, cap. II, §18.

19 "The estate of hostility and war being such, as thereby nature itself is destroyed, and men kill one another [...] he therefore that desireth to live in such an estate, as is the estate of liberty and right of all to all, contradicteth himself. For every man by natural necessity desireth his own good, to which this estate is contrary, wherein we suppose contention between men by nature equal, and able to destroy one another" [HOBBES, Thomas. The Elements of Law Natural and Politic. Cambridge: Cambridge University Press, 1928 [1640], cap. 14, §12]. 20 "The argument against the fool shows, I think, that Hobbes does not in fact appeal to a notion of moral obligation (as normally understood) in this argument" [RAWLS, John. Lectures on the History of Political Philosophy. Cambridge, MA: Harvard University Press, 2007, p. 70]. 21 "[...] promises are to be [kept] even at some loss, as things turn out, to one's advantage, even when this is a certain overall loss" [RAWLS, John. Lectures on the History of Political Philosophy. Cambridge, MA: Harvard University Press, 2007, p. 70].
} 
um dever moral ou de um ato da pessoa. Seja como for, o importante é que se distinga entre ter uma obrigação e ser obrigado a. ${ }^{22}$ De acordo com o primeiro conceito, de ter uma obrigação, esta permanece válida ainda que haja motivos para não cumpri-la ${ }^{23}$. É precisamente este o ponto que traduziria a ideia de sacrifício presente na definição do conceito de obrigação ${ }^{24}$.

Uma possibilidade de explicar o que significa essa perda total em Rawls seria tomar a prioridade do justo sobre o bem de forma absoluta. Não se vê outra alternativa para uma tal explicação, senão o recurso a Kant, especificamente ao seu tratamento do jus necessitatis. Com efeito, nesse particular, Kant afirma ser um dever incondicional não tirar a vida de outro que não age injustamente, ao passo que é um dever condicional preservar a própria vida. ${ }^{25}$ Aqui se entende como pode haver uma perda total decorrente de uma obrigação estabelecida categoricamente pela razão. A perda total é a própria vida para dar cumprimento ao dever incondicional de não tirar a vida de outro. "Na ética tradicional, a proibição de matar seres humanos inocentes é absoluta." ${ }^{26}$ Ora, como o próprio Rawls observa, a lei natural não fundamenta uma obrigação absoluta, já que depende do que os outros farão ${ }^{27}$. Ela não é uma obrigação que se cumpre unilateralmente como um dever absoluto, pois fazer isso seria se expor como presa aos outros, como estabelece o cap. XIV do Leviathan ${ }^{28}$.

A segunda condição, por seu turno, refere-se à equidade e ao equilíbrio de perdas e vantagens ${ }^{29}$. Um contrato ou uma promessa, para ser razoável,

${ }^{22}$ HART, H. L. A. The Concept of Law. 2. ed., Oxford: Clarendon Press, 1994 [1961], p. 82.

23 "Thus the statement that a person had an obligation, e.g. to tell the truth or report for military service, remains true even if he believed (reasonably or unreasonably) that he would never be found out and had nothing to fear from disobedience" [HART, H. L. A. The Concept of Law. 2. ed., Oxford: Clarendon Press, 1994 [1961], p. 83].

24 "Hence obligations and duties are thought of as characteristically involving sacrifice or renunciation, and the standing possibility of conflict between obligation or duty and interest is, in all societies, among the truisms of both the lawyer and the moralist" [HART, H. L. A. The Concept of Law. 2. ed., Oxford: Clarendon Press, 1994 [1961], p. 87].

${ }^{25}$ KANT, Immanuel. Sobre a expressão corrente: isso pode ser correcto na teoria, mas nada vale na prática. [Trad. Artur Morão]. Covilhã: Lusofia Press, s/d [1793]. [http://www.lusosofia.net/], p. 31-32 [TP, AA 08: 300 nota].

${ }^{26}$ RACHELS, James, RACHELS, Stuart. The Elements of Moral Philosophy. 7. ed., New York: McGraw-Hill, 2012, p. 7.

${ }^{27}$ RAWLS, John. Lectures on the History of Political Philosophy. Cambridge, MA: Harvard University Press, 2007, p. 66.

28 "But if other men will not lay down their Right, as well as he; then there is no Reason for any one, to devest himselfe of his: For that were to expose himselfe to Prey, (which no man is bound to) rather than to dispose himselfe to Peace. This is that Law of the Gospell; Whatsoever you require that others should do to you, that do ye to them. And that Law of all men, Quod tibi fieri non vis, alteri ne feceris". [HOBBES, Thomas. Leviathan, or Matter, Form, and Power of a Commonwealth Ecclesiastical and Civil. [Edited by C.B. Macpherson]. London: Penguin, 1968 [1651], chap. XIV].

29 " $[\ldots]$ are considerations of fairness and the distributions of gains and losses among, e.g., the parties to an agreement" [RAWLS, John. Lectures on the History of Political Philosophy. Cambridge, MA: Harvard University Press, 2007, p. 70]. 
tem que satisfazer certas condições de equidade ${ }^{30}$. Sabidamente, "Hobbes diz que uma promessa é obrigatória mesmo quando alguém é coagido a fazê-la"31, conforme o Leviathan, cap. XIV.

Rawls sumariza a conclusão que se segue de suas duas teses do seguinte modo:

Assim, concluo que a visão de Hobbes, como expressa em sua resposta ao tolo, não permite espaço para a noção comum de obrigação moral (promessas, por exemplo), porque essa noção envolve alguma preocupação com a justiça (por exemplo, as circunstâncias sob as quais promessas são feitas) e com o cumprimento das promessas, mesmo quando poderíamos fazer melhor. E se considerarmos estritamente a razão prática de Hobbes, parece que ambos estão descartados. ${ }^{32}$

Essa interpretação de Rawls pode ser melhor compreendida a partir de um estudo de Nagel sobre a matéria. Nagel comunga com a tese de Taylor-Warrender de que a teoria da motivação baseada no autointeresse “[...] é a ruína de qualquer tentativa de colocar uma construção verdadeiramente moral no conceito de obrigação de Hobbes" ${ }^{\prime 3}$, de tal forma que "um sentimento genuíno de obrigação moral nunca pode desempenhar um papel em suas deliberações" ${ }^{34}$. Sabidamente, essa é razão pela qual Warrender e Taylor procuraram por um outro fundamento da obrigação em Hobbes. Seja como for, Nagel não segue esse caminho. O que ele faz é retirar a consequência da tese avançada, qual seja, "[...] A obrigação moral genuína simplesmente não atua no Leviatã, mas o que Hobbes chama de obrigação moral se baseia exclusivamente em considerações de interesse próprio racional" ${ }^{35}$

Sem embargo dessas teses de Nagel e de Rawls, poder-se-iam fazer duas defesas em nome de Hobbes.

A primeira delas é com relação ao primeiro déficit da dedução do razoável a partir do racional, qual seja, um déficit deontológico, haja vista a obrigação em Hobbes nunca exigir uma perda total sobre a sensibilidade. De fato, o sistema de Hobbes não comporta uma perda global se isso envolver o caso extremo. A consideração de casos extremos pode ser usada para testar uma certa teoria, o que o próprio Kant parece fazer no

\footnotetext{
${ }^{30}$ RAWLS, John. Lectures on the History of Political Philosophy. Cambridge, MA: Harvard University Press, 2007, p. 70.

${ }^{31}$ RAWLS, John. Lectures on the History of Political Philosophy. Cambridge, MA: Harvard University Press, 2007, p. 70.

${ }^{32}$ RAWLS, John. Lectures on the History of Political Philosophy. Cambridge, MA: Harvard University Press, 2007, p. 71.

${ }^{33}$ NAGEL, Thomas. Hobbes's Concept of Obligation. Philosophical Review. V. 68, 1959, p. 74.

${ }^{34}$ NAGEL, Thomas. Hobbes's Concept of Obligation. Philosophical Review. V. 68, 1959, p. 75.

${ }^{35}$ NAGEL, Thomas. Hobbes's Concept of Obligation. Philosophical Review. V. 68, 1959, p. 69.
} 
seu texto Sobre a expressão corrente: isso pode ser correto na teoria, mas nada vale na prática, por exemplo, ao se pronunciar sobre o direito no estado de necessidade. No caso de Hobbes, Lloyd afirma que os casos extremos são essenciais ${ }^{36}$. Quais seriam esses casos extremos que ela considera? Basicamente os fundamentalismos religiosos, os quais teriam compromissos transcendentes e não negociáveis: mártires, seguidores do Hamas, Al Qaeda e Jihad. ${ }^{37}$ Ainda que ela não analise o estado de necessidade, retém-se para o presente estudo a sua dicção de que a teoria de Hobbes não pode simplesmente ignorar os casos extremos ${ }^{38}$. Também a teoria de Kant não ignorou casos extremos, como aquele do estado de necessidade do qual aqui se trata.

Nesse ponto, Hobbes pode alegar, em sua defesa, que mantém a coerência de seu sistema, mesmo no caso extremo. Deveras, o fim que fundamenta a lei natural é o mesmo que excepciona a lei natural na circunstância extrema. Nesse diapasão, seria de se perguntar se Rawls estaria disposto a manter o que Kant manteve em relação ao caso extremo ou se ele não tergiversaria com argumentos hobbesianos, por exemplo, na defesa da segurança e da ordem pública. Com efeito, eis o que ele afirma: "as seitas tolerantes têm o direito de não tolerar o intolerante em pelo menos uma circunstância, a saber, quando sinceramente e com razão acreditam que a intolerância é necessária para sua própria segurança. [...] Pois, nunca pode ser uma vantagem para os homens, de um ponto de vista geral, renunciar ao direito à autoproteção" ${ }^{39}$. Em vez de Rawls destacar uma argumentação pró-legítima defesa, ainda que preventiva, ele parece usar argumentos semelhantes àqueles utilizados no estado de necessidade. A defesa legítima presume um ato injusto por uma das partes. No entanto, Rawls não foca a sua análise sobre o caráter injusto da ação do intolerante, em vez disso, ele foca sobre a vantagem da autopreservação.

O segundo ponto de defesa é que o sistema de Hobbes estatui condições mínimas de equidade. Tais condições poderiam ser verificadas mediante duas evidências. A primeira é que o escravo não tem obrigação, haja vis-

\footnotetext{
${ }^{36}$ LLOYD, S. A. Morality in the Philosophy of Thomas Hobbes: Cases in the Law of Nature. Cambridge: Cambridge University Press, 2009, p. 399.

${ }^{37}$ LLOYD, S. A. Morality in the Philosophy of Thomas Hobbes: Cases in the Law of Nature. Cambridge: Cambridge University Press, 2009, p. 397. Ela acusa a proposta do contratualismo moral de Gauthier de ter desconsiderado tais casos extremos [LLOYD, S. A. Morality in the Philosophy of Thomas Hobbes: Cases in the Law of Nature. Cambridge: Cambridge University Press, 2009, p. 399].

38 "But for Hobbes's project, the 'extreme' cases are central. They are ineliminable from his account of disorder, and so cannot be excluded from any model of rational cooperation adequate to address that problem. No model that required their exclusion could be in a relevant sense Hobbesian" [LLOYD, S. A. Morality in the Philosophy of Thomas Hobbes: Cases in the Law of Nature. Cambridge: Cambridge University Press, 2009, p. 399].

${ }^{39}$ RAWLS, John. A Theory of Justice. [Revised Edition]. Oxford: Oxford University Press, 1999 [1971], p. 191-192, §35.
} 
ta o contrato por ele firmado não se constituir por um ato de liberdade, ainda que seja a liberdade tal qual definida por Hobbes, a saber, como não-impedimento. A segunda reside naquelas cláusulas inquinadas de nulidade absoluta, cuja desobediência não se constitui em injustiça. Como bem sumariza Nagel, há condições para que uma obrigação se estabeleça,

que 'podem ser resumidas pela afirmação de que o indivíduo não pode ser obrigado quando isso for logicamente impossível.' Entre essas estão as condições que a lei deve ser conhecida, que o autor dela deve ser conhecido e que, se um homem está em sério risco de morte, ele é escusado se agir contra a lei para se salvar. ${ }^{40}$.

De mais a mais, ter-se-ia que perquirir se a dicção rawlsiana das condições de equidade faz uso de argumentos estritamente deontológicos, nos moldes kantianos, capazes de suportar uma perda total, ou se ele não operacionaliza tais condições de um modo semelhante a Hobbes, por exemplo, quando argumenta contra o princípio da utilidade média por este não honrar um senso de justiça que teria que estar em harmonia com os interesses não benevolentes das partes na posição original, o que ele traduz, inclusive, em regras da psicologia humana, como se pode ver nos parágrafos 27,28 , 29 e 30 de $A$ Theory of Justice.

\section{Da obrigação em Kant}

Kant, por seu turno, tem um conceito de obrigação de outra estirpe. Ela provém de uma lei ordenada pela razão que toma a forma do dever para uma racionalidade sensível, um dever categórico, o qual obriga independentemente dos fins que uma tal criatura possa ter. $\mathrm{O}$ imperativo categórico é um critério para determinar a lei para um ser racional finito, a qual, por isso mesmo, tem a forma de um dever, o que significa que inclui em si a lei e a coação. ${ }^{41} \mathrm{O}$ caráter estritamente deontológico do conceito de obrigação significa que a incondicionalidade da mesma se distingue de modo essencial, constituindo-se em um campo totalmente diverso, sem consideração com qualquer outro fim que se possa ter. ${ }^{42}$

\footnotetext{
${ }^{40}$ NAGEL, Thomas. Hobbes's Concept of Obligation. Philosophical Review. V. 68, 1959, p. 73

${ }^{41}$ KANT, Immanuel. A metafísica dos costumes. [Trad. J. Lamego]. Lisboa: Fundação Calouste Gulbenkian, 2005 [1797], p. 222 [RL, AA 06: 222-223].

42 "A máxima que prescreve observar incondicionalmente, sem qualquer consideração por um fim tomado como princípio, uma lei do livre arbítrio (isto é, o dever) que impera categoricamente distingue-se de modo essencial, isto é, segundo a espécie, da máxima que nos prescreve seguir o fim (que em geral se chama felicidade) a nós proposto pela própria natureza como motivo para um certo modo de agir. A primeira máxima é, de facto, boa em si mesma, mas não a segunda; esta, em caso de colisão com o dever, pode ser muito má. [...] Mas o estado em que, no caso de colisão de certos fins meus com a lei moral do dever, sou consciente de preferir este último, não é apenas um estado melhor, mas o único que em
} 
No início da Doutrina do direito, nos parágrafos A, B e C da introdução, Kant distingue lei [Gesetz] e direito [Recht] (no sentido de justo). Assim, ele pode diferenciar uma doutrina do direito positivo - ou seja, uma doutrina do direito cuja preocupação é a lei [Gesetz, ius] no sentido da lei positiva, - de uma doutrina do direito que tem por objeto o direito justo [Recht, iustum].

É justamente na determinação da justiça que parece haver uma correlação entre o imperativo categórico e o princípio universal do direito. O imperativo categórico é assim formulado por Kant: "age apenas segundo a máxima pela qual possas ao mesmo tempo querer que ela se torne uma lei universal." 43 Segundo Gregor, "O imperativo categórico é o princípio de todas as leis morais, sejam jurídicas ou éticas." ${ }^{44}$ Desse modo, o princípio universal do direito poderia ser considerado como uma aplicação do imperativo categórico para o âmbito jurídico:45 "É justa [recht] toda ação segundo a qual ou segundo cuja máxima a liberdade do arbítrio de cada um pode coexistir com a liberdade de qualquer um segundo uma lei universal, etc." ${ }^{46}$. Como consequência desse princípio, segue-se também o conceito de injustiça: "Se minha ação, portanto, ou em geral meu estado, pode coexistir com a liberdade de qualquer um segundo uma lei universal, então aquele que me impede nisto é injusto [Unrecht] para comigo, pois este impedimento (esta resistência) não pode coexistir com a liberdade segundo leis universais". ${ }^{47}$

Deveras, tudo o que o imperativo categórico ordena pode coexistir com a liberdade de qualquer um, mas nem tudo o que pode coexistir com a liberdade de qualquer um é ordenado pelo imperativo categórico. Dito de

si é bom: é um bem de um campo totalmente diverso, onde não se têm em consideração os fins que se me podem oferecer (nem, por conseguinte, o seu conjunto, a felicidade) e onde o que constitui o princípio determinante do arbítrio não é a sua matéria (um objecto que lhe é dado como fundamento), mas a simples forma da legalidade universal da sua máxima. Por conseguinte, de nenhum modo se pode dizer que cada estado, que eu prefiro a todo o outro modo de ser, deve por mim ser incluído na felicidade. Pois, em primeiro lugar, devo estar certo de que não ajo contra o meu dever; só depois me é permitido olhar à volta em busca da felicidade, contanto que eu a possa conciliar com o meu estado moralmente (e não fisicamente) bom." [KANT, Immanuel. Sobre a expressão corrente: isso pode ser correcto na teoria, mas nada vale na prática. [Trad. Artur Morão]. Covilhã: Lusofia Press, s/d [1793]. [http://www. lusosofia.net/], p. 11-12 [TP, AA 08: 282-283]].

${ }^{43}$ KANT, Immanuel. Fundamentação da metafísica dos costumes. [Trad. G. A. de Almeida: Grundlegung zur Metaphysik der Sitten]. São Paulo: Discurso Editorial/Barcarolla, 2009 [1785], p. 421 [GMS, AA 04: 421].

${ }^{44}$ GREGOR, Mary J. Law of Freedom: A Study of Kant's Method of Applying the Categorical Imperative in the 'Methapysik der Sitten'. Oxford: Blackwell, 1963, p. 30.

${ }^{45}$ Essa é uma interpretação com a qual concorda ALMEIDA, Guido Antônio de. Sobre o princípio e a lei universal do Direito em Kant. Kriterion. N. 114, 2006, p. 209-222.

${ }^{46}$ KANT, Immanuel. A metafísica dos costumes. [Trad. J. Lamego]. Lisboa: Fundação Calouste Gulbenkian, 2005 [1797], p. 230 [RL, AA 06: 230].

${ }^{47}$ KANT, Immanuel. A metafísica dos costumes. [Trad. J. Lamego]. Lisboa: Fundação Calouste Gulbenkian, 2005 [1797], p. 230-231 [RL, AA 06: 230-231]. 
outro modo, o descumprimento de uma parte do conjunto dos deveres ou das leis ordenadas pelo imperativo categórico pode perfeitamente coexistir com a liberdade de qualquer um. Por exemplo, a avareza ou mesmo o suicídio pode, na maior parte dos casos, ser compatível com a liberdade de todos, pois, em princípio, não causa dano a ninguém. Diz-se na maior parte dos casos e em princípio porque pode ser o caso que, por exemplo, um pai avaro ou suicida prejudique os seus filhos. Ora, o conceito de direito como autorização [Befugniß], que Mulholland nomina titles, ${ }^{48}$ chama a atenção para essa incongruência entre o que ordena o imperativo categórico e o que permite o princípio universal do direito. Como dito, o imperativo categórico é um critério para determinar a lei para um ser racional finito, a qual, por isso mesmo, tem a forma de um dever, o que significa que já inclui em si a coação. ${ }^{49}$ Nesse momento, ele é indiferente à ética e ao direito, como sustenta Gregor..$^{50}$ Esse aspecto teria sido obscurecido porque Kant começou a Fundamentação com o conceito de vontade boa, o qual é próprio da ética. ${ }^{51} \mathrm{Na}$ verdade, o dever em geral, ou seja, a lei para um ser racional finito, a necessidade moral, pode ser estabelecida sem relação com os motivos. Lei e motivo são diferentes. Kant começa a Metafísica dos costumes com o direito justamente porque a coação que é analiticamente conectada com ele faz uma seção nas possibilidades motivacionais e, com isso, também força a uma divisão do conjunto das leis ou deveres que o imperativo categórico determina: "A positividade do direito força uma divisão da autonomia, que não possui equivalente no campo da moral." 52

A primeira consequência dessa seção no conjunto dos deveres determinados pelo imperativo categórico é que nem todo dever pode ser objeto de coação externa. É o caso de uma parte dos deveres para consigo e dos deveres de virtude. Essa é uma consequência determinada pela possibilidade mesma da coação externa, a qual é imprópria para estabelecer um

\footnotetext{
${ }^{48}$ MULHOLLAND, Leslie Arthur. Kant's System of Rights. New York: Columbia University Press, 1990, p. 220.

${ }^{49}$ KANT, Immanuel. A metafísica dos costumes. [Trad. J. Lamego]. Lisboa: Fundação Calouste Gulbenkian, 2005 [1797], p. 222 [RL, AA 06: 222-223].

${ }^{50}$ GREGOR, Mary J. Law of Freedom: A Study of Kant's Method of Applying the Categorical Imperative in the 'Methapysik der Sitten'. Oxford: Blackwell, 1963, p. 30.

${ }^{51}$ GREGOR, Mary J. Law of Freedom: A Study of Kant's Method of Applying the Categorical Imperative in the 'Methapysik der Sitten'. Oxford: Blackwell, 1963, p. 18.

52 HABERMAS, Jürgen. Direito e democracia: entre faticidade e validade. [v. II]. [Trad. F. B. Siebeneichler: Faktizität und Geltung: Beiträge zur Diskurstheorie des Rechts und des demokratischen Rechtsstaats]. Rio de Janeiro: Tempo Brasileiro, 1997, p. 310, posfácio. Sabidamente, ainda que Habermas possa sufragar a interpretação de Gregor, haja vista a sua própria interpretação de Kant ser muito parecida com a dela, a conclusão, em geral, que Habermas retira dessa premissa é bem diferente daquela de Kant. Segundo Habermas, "se a autonomia das pessoas do direito abrange mais do que a autonomia em sentido moral, o direito não pode ser entendido como um caso especial da moral." [HABERMAS, Jürgen. Direito e democracia: entre faticidade e validade. [v. I e II]. [Trad. F. B. Siebeneichler: Faktizität und Geltung: Beiträge zur Diskurstheorie des Rechts und des demokratischen Rechtsstaats]. Rio de Janeiro: Tempo Brasileiro, 1997, p. 311, posfácio].
} 
dever de virtude, "pois razões analíticas impedem que um agir por dever, isto é, a obediência ao direito por motivos morais, possa ser imposto com o uso da coerção" ${ }^{\prime \prime 3}$.

A segunda consequência dessa seção decorre da sua restrição ao âmbito do externo, para o qual a razão determina um segundo critério de correção, a justiça. Destarte, toda lei moral é compatível com a coexistência da liberdade de todos. Por isso, no texto contra Constant Kant pode afirmar que o cumprimento do dever de veracidade só causa prejuízo por acaso. ${ }^{54}$ Contudo, a coação força a uma limitação do escopo do dever. Se a virtude, ou a vontade boa, não pode ser imposta pela coação, então, esta terá que se restringir ao externo, ou seja, à coexistência das liberdades. Ora, é possível pensar o direito como um sistema de coerção recíproca, no qual não opera o conceito de obrigação. Desse modo, Kant não vai ao ponto de identificar direito e direito justo. Em tese, o direito justo é aquele que coage à prática dos deveres para com os outros, pois são estes cujo descumprimento causa dano. Dano é uma interferência indevida na liberdade dos outros. Portanto, sob o ponto de vista do conteúdo da norma poder-se-ia pensá-lo como sendo moral, muito embora a forma de cumprimento não possa ser concebida em termos éticos, ou seja, como virtude.

Essas duas formulações estão na base do conceito de obrigação em Kant: "Obrigatoriedade é a necessidade de uma ação livre sob um imperativo categórico da razão". ${ }^{55} \mathrm{Em}$ razão de afirmações como essa, Kant parece desenhar o começo da Doutrina do direito com base no conceito de obrigação, no conceito de dever, não naquele de direito, como seria de se esperar. Ele próprio registra esse questionamento:

Mas por que a doutrina dos costumes (moral) é ordinariamente (particularmente por Cícero) intitulada a doutrina dos deveres e não também dos direitos, dado que uns se referem aos outros? - O fundamento é este: Nós só conhecemos nossa própria liberdade (de que procedem todas as leis morais, portanto também todos os direitos tanto quanto os deveres) através do imperativo moral, que é uma proposição que ordena um dever, a partir do qual pode ser desenvolvida posteriormente a faculdade de obrigar os outros, i. e., o conceito do direito. ${ }^{56}$

\footnotetext{
${ }^{53}$ HABERMAS, Jürgen. Direito e democracia: entre faticidade e validade. [v. I]. Rio de Janeiro: Tempo Brasileiro, 1997, p. 48.

54 "Se quisermos manter os nomes das pessoas que aqui se citaram, o "filósofo francês" confundiu a acção pela qual alguém lesa [schadet] (nocet) outrem, ao proferir a verdade cuja confissão ele não pode evitar, com a outra pela qual comete contra ele uma injustiça [Unrecht] (laedit). Só por acaso (casus) é que a veracidade da declaração prejudicava [schadete] o habitante da casa, e não por uma acção livre (no sentido jurídico)." [KANT, Immanuel. Sobre um suposto direito de mentir. [Trad. Artur Morão]. Covilhã: Lusofia Press, s/d [1797]. [http:// www.lusosofia.net/ Original disponível em: http://www.zeno.org/], p. 7 [VRML, AA 08: 428]]. ${ }^{55}$ KANT, Immanuel. A metafísica dos costumes. [Trad. J. Lamego]. Lisboa: Fundação Calouste Gulbenkian, 2005 [1797], p. 222 [RL, AA 06: 222].

${ }^{56}$ KANT, Immanuel. A metafísica dos costumes. [Tr. J. Lamego]. Lisboa: Fundação Calouste Gulbenkian, 2005 [1797], p. 239 [RL, AA 06: 239].
} 
Nesse particular, como observado, há uma forte conexão entre o imperativo categórico e o princípio universal do direito, tanto que Gregor os concebe em uma relação de gênero e de espécie, respectivamente. Explicar tal correlação levanta algumas dificuldades no pensamento kantiano. Tais dificuldades decorrem precisamente da distinção que há entre o direito e o dever. Melhor dito, deveres jurídicos são distintos de deveres morais, a começar pela motivação que está à base de cada um.

A distinção dos domínios do direito e da virtude ou da ética depende, como visto, do que caracteriza o direito, ou seja, a coação: "Direito e faculdade de coagir significam, portanto, a mesma coisa" 57 . É esse elemento que força a uma restrição dos conteúdos morais que podem ser objeto de regulação jurídica, bem como força a outra precisão conceitual, qual seja, aquela entre a lei e o motivo. ${ }^{58}$ Ora, coagir a ter um fim é autocontraditório. ${ }^{59}$ Desse modo, a razão se vê forçada a pensar um sistema de deveres que não pode contar com a motivação pela vontade boa. Essa formulação é difícil de perceber, segundo Gregor, porque o imperativo categórico é formulado, por Kant, na Fundamentação, em conexão com o conceito de vontade boa: "No entanto, como a ênfase de Kant nesses trabalhos anteriores é sobre a imposição autônoma do dever em ações moralmente boas, é difícil realizar, neles, a abstração de questões de motivação que apresentariam o imperativo categórico como o princípio indiferenciado em relação à lei ética e jurídica." ${ }^{60}$ Como já afirmado, o imperativo categórico traz em si a lei e a coação da lei, pois esta última está sob a forma de uma ordem. Porém, não se pode esquecer que o imperativo categórico é, antes de tudo, a formulação da lei moral para um ser racional finito. O caráter imperativo da lei força a sua conexão com a vontade boa, a qual não tem relação direta com a lei moral, haja vista esta ser lei moral também para um ser racional perfeito, para quem ela não é um imperativo:

Ele [o imperativo] se diferencia de uma lei prática, a qual certamente também representa a necessidade de uma ação, mas sem levar em consideração se

\footnotetext{
${ }^{57}$ KANT, Immanuel. A metafísica dos costumes. [Trad. J. Lamego]. Lisboa: Fundação Calouste Gulbenkian, 2005 [1797], p. 232 [RL, AA 06: 232].

58 "Toda legislação (prescreva ações internas ou externas, e essas, ou a priori, através da simples razão, ou através do arbítrio de um outro) contém duas partes: primeiro, uma lei, que representa objetivamente como necessária a ação que deve acontecer, i. e., que faz da ação um dever, segundo, um móbil [Triebfeder], que liga subjetivamente à representação da lei o fundamento de determinação do arbítrio para esta ação; a segunda parte é, pois, esta: que a lei faz do dever um móbil [dass das Gesetz die Pflicht zur Triebfeder macht]. Pela primeira, a ação é representada como dever, o que é um mero conhecimento teórico [ein blosses theoretisches Erkenntnis] da determinação possível do arbítrio, i. e., de regras práticas; pela segunda, a obrigação de assim agir é ligada efetivamente no sujeito ao fundamento de determinação do arbítrio" [KANT, Immanuel. A metafísica dos costumes. [Trad. J. Lamego]. Lisboa: Fundação Calouste Gulbenkian, 2005 [1797], p. 218 [RL, AA 06: 218]].

${ }^{59}$ KANT, Immanuel. A metafísica dos costumes. [Trad. J. Lamego]. Lisboa: Fundação Calouste Gulbenkian, 2005 [1797], p. 281 [RL, AA 06: 381].

${ }^{60}$ GREGOR, Mary J. Law of Freedom: A Study of Kant's Method of Applying the Categorical Imperative in the 'Methapysik der Sitten'. Oxford: Blackwell, 1963, p. 18.
} 
essa ação em si já se encontra interiormente de forma necessária no sujeito agente (por exemplo, em um ser santo), ou se ela é contingente (como no homem), pois, onde se dá o primeiro, não há imperativo. ${ }^{61}$

Ora, é precisamente a consideração da motivação que determina a distinção de uma legislação jurídica e ética. A consideração da motivação determinará para Kant duas legislações, ou seja, duas formas de cumprimento da mesma lei. Nesse sentido, não é a vontade boa que seciona o conjunto dos deveres entre aqueles jurídicos e morais, mas a coação. É a coação que determina uma seção no domínio dos deveres.

É esse elemento fundamental na argumentação, a coação, que força Kant a escrutinar um critério para tornar justo o uso da coação. O predicado da vontade boa não porta maiores problemas para a sua consonância com a liberdade. O seu próprio conceito parece implicar que seja um ato livre, pois só o próprio sujeito pode se dar um fim. Um fim não pode ser imposto. Porém, o predicado da coerção externa, ligado analiticamente ao direito, porta problemas especiais para ser compatível com a liberdade. Boa parte da filosofia do direito kantiana consiste em reconciliar a coação externa com a liberdade. Ao fim, o princípio universal do direito é que definirá um critério pelo qual a coação pode ser reconciliada com a liberdade. Ora, o princípio universal do direito estabelece precisamente um critério de justiça das ações. Sendo a ação justa aquela que não causa dano a ninguém, impedir um uso da liberdade que não causa dano a ninguém é injustiça. Portanto, se a coação for usada como um impedimento de um impedimento a uma liberdade justa, ela também será justa.

Como dito, é a coação que determina uma seção nos deveres, o que implica pensá-los sem o conceito de vontade boa. Vontade boa e coação esboçam duas formas de cumprir leis. Desse modo, do conjunto de deveres ditados pelo imperativo categórico, apenas uma parte deles seria passível de coação externa: “O princípio da obrigação jurídica, aja de maneira que sua máxima possa se tornar uma lei universal, é um princípio somente para ações externas; o da obrigação ética é: faça dela a sua máxima, para agir como se você estivesse dando a lei universal através dessa máxima, o que é também um princípio para o querer." ${ }^{22}$ Assim, é possível pensar o sistema prático de deveres baseados na coação externa ao menos de três maneiras.

A primeira forma é pensá-lo como um sistema de deveres jurídicos. Se ele for pensado sob o ponto de vista da obrigação ética, todos os deveres podem ser cumpridos segundo a vontade boa, desde que a lei seja justa: "a doutrina do direito e a doutrina da virtude, se distinguem, então, bem

${ }^{61}$ KANT, Immanuel. A metafísica dos costumes. [Trad. J. Lamego]. Lisboa: Fundação Calouste Gulbenkian, 2005 [1797], p. 222 [RL, AA 06: 222].

${ }^{62}$ GREGOR, Mary J. Law of Freedom: A Study of Kant's Method of Applying the Categorical Imperative in the 'Methapysik der Sitten'. Oxford: Blackwell, 1963, p. 29. 
menos por deveres diferentes que pela diferença de legislação que associa à lei um móbil antes que um outro."63 Ou seja, para "leis idênticas, as máximas dos agentes podem ser muito diferentes." ${ }^{44}$ Como bem anota Gregor, "Até agora, consideramos o direito e a ética como sistemas de deveres. Mas, se olharmos para a ética, não do ponto de vista dos deveres especiais que ela prescreve, mas sim do da obrigação própria a ela, então, a ética tem a ver com todos os nossos deveres." ${ }^{65}$ É claro que pode haver deveres de natureza estritamente ética, mas isso não impede que deveres jurídicos sejam cumpridos pelos motivos de uma vontade boa, ou seja por virtude, dede que, como dito, sejam regras justas. $O$ que não pode ocorrer é que o sistema seja baseado nessa forma de cumprimento do dever ${ }^{66}$. Destarte, “De acordo com a legislação ética, nosso dever consiste não apenas em agir consistentemente com a lei universal, mas em querer as ações legais simplesmente porque são legais." 67

A segunda forma de pensá-lo é como um sistema de coação recíproca, o qual pode abstrair do caráter obrigacional dos deveres:

O direito estrito pode ser representado também como a possibilidade de uma coação recíproca geral concordante com a liberdade de qualquer um segundo leis universais. Esta proposição quer dizer que o direito não deve ser pensado como composto de duas partes, a saber, a obrigação segundo uma lei e a faculdade, daquele que obriga o outro através de seu arbítrio, de coagi-lo ao cumprimento da obrigação, mas pode-se fazer o conceito do direito consistir imediatamente na possibilidade da conexão da coação recíproca universal com a liberdade de qualquer um [...] Direito e faculdade de coagir significam, portanto, a mesma coisa. ${ }^{68}$

Pode-se perceber, no início da Doutrina do direito, o esforço teórico de Kant para pensar o direito despido do conceito de obrigação, a qual é própria do domínio da ética, já que exige, em última análise, o conceito de vontade

\footnotetext{
${ }^{63}$ KANT, Immanuel. A metafísica dos costumes. [Trad. J. Lamego]. Lisboa: Fundação Calouste Gulbenkian, 2005, MS, AA 06: 220.

${ }^{64}$ KANT, Immanuel. A metafísica dos costumes. [Trad. J. Lamego]. Lisboa: Fundação Calouste Gulbenkian, 2005, MS, AA 06: 225.

${ }^{65}$ GREGOR, Mary J. Law of Freedom: A Study of Kant's Method of Applying the Categorical Imperative in the 'Methapysik der Sitten'. Oxford: Blackwell, 1963, p. 28.

${ }_{66}$ "Our juridical duties, accompanied by ethical obligation to fulfill them without regard for the possibility of external compulsion, remain juridical duties because the moral necessity of the actions is independent of our inner attitude of will and compulsion by others remains morally possible. By this they are distinguished from directly ethical duties; but inner legislation makes them 'indirectly ethical'. Ethics, as Kant puts it takes up juridical duties, in so far as they are duties, into the position of motives in its own legislation" [GREGOR, Mary J. Law of Freedom: A Study of Kant's Method of Applying the Categorical Imperative in the 'Methapysik der Sitten'. Oxford: Blackwell, 1963, p. 28-29].

${ }^{67}$ GREGOR, Mary J. Law of Freedom: A Study of Kant's Method of Applying the Categorical Imperative in the 'Methapysik der Sitten'. Oxford: Blackwell, 1963, p. 29.

${ }^{68}$ KANT, Immanuel. A metafísica dos costumes. [Trad. J. Lamego]. Lisboa: Fundação Calouste Gulbenkian, 2005 [1797], p. 232 [RL, AA 06: 232].
} 
boa. Ora, a concepção do sistema jurídico como uma coação recíproca é o pensamento do direito estrito, ou seja, despido da noção de obrigação ${ }^{69}$.

A terceira forma é pensar a sistema como sendo propriamente um sistema de direitos, ou seja, como uma autorização [Befugniß], uma liberdade, uma pretensão para fazer o que não causa dano. O conceito de autorização opera de vários modos no texto de Kant, sendo sempre o verso da medalha de uma ação que não causa dano.

No âmbito moral, o cumprimento do imperativo categórico não causa dano, a não ser por acaso, por acidente, logo, há uma autorização "para fazer ou deixar de fazer algo a seu bel-prazer"70 as ações moralmente indiferentes, aquelas que se põem como o que resta depois da varredura, do filtro do imperativo categórico: "Lícita é uma ação (licitum) que não é contrária à obrigação; e esta liberdade não restringida por nenhum imperativo contrário chama-se a faculdade (facultas moralis). [...] Uma tal ação chama-se moralmente indiferente (indifferens, adiaphoron, res merae facultatis)." ${ }^{71}$ Tais ações poderiam configurar o domínio daquilo que pode ser buscado como plano de felicidade: "Pois, em primeiro lugar, devo estar certo de que não ajo contra o meu dever; só depois me é permitido olhar à volta em busca da felicidade, contanto que eu a possa conciliar com o meu estado moralmente (e não fisicamente) bom."72

No que concerne ao direito, por um lado, considerado como faculdade moral, ele consiste em uma autorização para fazer o que o dever categórico ordena ou proíbe: "A todo dever corresponde um direito, considerado como faculdade (facultas moralis generatim); mas nem a todos os deveres correspondem direitos por parte de outrem a coagir alguém (facultas iuridica); sendo que estes se chamam especificamente deveres jurídicos". ${ }^{73}$ Por outro lado, o direito implica uma autorização bem mais ampla do

69 "True, we are conscious that the actions enjoined by juridical laws are duties and that we ought to perform them without regard for the compulsion that can be brought to bear on us. But this consciousness of our ethical obligation to juridical duties is precisely what Kant intends to exclude from the notion of Law by defining it merely as the possibility of universal reciprocal compulsion. So far as legal obligation is concerned, it would be redundant to include within the definition of Law both moral authority to compel and obligation according to the law. And, where strict Law is concerned, the fact that we are also under ethical obligation to fulfill our juridical duties is not relevant" [GREGOR, Mary J. Law of Freedom: A Study of Kant's Method of Applying the Categorical Imperative in the 'Methapysik der Sitten'. Oxford: Blackwell, 1963, p. 44].

${ }^{70}$ KANT, Immanuel. A metafísica dos costumes. [Trad. J. Lamego]. Lisboa: Fundação Calouste Gulbenkian, 2005 [1797], p. 223 [RL, AA 06: 223].

${ }^{71}$ KANT, Immanuel. A metafísica dos costumes. [Trad. J. Lamego]. Lisboa: Fundação Calouste Gulbenkian, 2005 [1797], p. 222-223 [RL, AA 06: 222-223].

${ }^{72}$ KANT, Immanuel. Sobre a expressão corrente: isso pode ser correcto na teoria, mas nada vale na prática. [Trad. Artur Morão]. Covilhã: Lusofia Press, s/d [1793]. [http://www.lusosofia.net/], p. 11-12 [TP, AA 08: 282-283.

${ }^{73}$ KANT, Immanuel. A metafísica dos costumes. [Trad. J. Lamego]. Lisboa: Fundação Calouste Gulbenkian, 2005 [1797], p. 383 [TL, AA 06: 383]. [“Aller Pflicht correspondirt ein Recht, 
que esta, pois ela só encontra empecilho no que causar dano. ${ }^{74}$ Isso é o que se pode deduzir do princípio universal do direito, o qual pode ser formulado como o princípio de não causar dano: "Não faças mal [Unrecht] a ninguém (neminem laede) [...] (Lex juridica)." ${ }^{75}$

O direito é uma autorização de fazer o que não causa dano à liberdade dos outros. Se uma ação não causa dano a ninguém, os outros agem injustamente ao impedir esse uso da liberdade. É como se os outros não tivessem interesse de agir ao impedir uma ação que não lhes causa dano. Obviamente, não deve ser levado em consideração os desejos e necessidades dos outros, porque com isso o espectro do dano se ampliaria. Se a coação não pode impor um fim, a razão ordena a liberação de tais fins, mesmo os fins reais das necessidades e do desejo de felicidade. Dano para Kant é uma restrição indevida da liberdade. A restrição é indevida quando a liberdade por ela restringida pode coexistir com a liberdade de todos.

Para Kant os deveres são os mais fundamentais, pois é deles que se pode inferir, sob o ponto de vista do conteúdo, o direito de impor uma obrigação aos outros ${ }^{76}$. Segundo Gregor, a noção de dever, seja moral ou jurídica, é tão conectado com o conceito de obrigação ética que é melhor falar em termos de direitos e não de deveres ${ }^{77}$. E isso que leva ao estranho efeito de que no âmbito jurídico o princípio universal do direito, que para Gregor é uma aplicação do imperativo categórico, permite a busca de fins imorais, desde que não causem dano aos outros. Dito em outros termos, desde que sejam compatíveis com a liberdade dos outros, uma conclusão, aliás, que a própria comentadora não deixa de registrar ${ }^{78}$.

als Befugniß (facultas moralis generatim) betrachtet, aber nicht aller Pflicht correspondiren Rechte eines Anderen (facultas iuridica) jemand zu zwingen; sondern diese heißen besonders Rechtspflichten."]

74 "É evidente que na Ética, que nunca autoriza algo com base no fato de ser inofensivo, nenhuma falsidade deliberada ao expressar os seus próprios pensamentos pode recusar esta dura denominação (que só ostenta na doutrina do Direito quando causa lesão ao direito dos outros)" [KANT, Immanuel. A metafísica dos costumes. [Trad. J. Lamego]. Lisboa: Fundação Calouste Gulbenkian, 2005 [1797], p. 429 [TL, AA 06: 429]].

${ }^{75}$ KANT, Immanuel. A metafísica dos costumes. [Trad. J. Lamego]. Lisboa: Fundação Calouste Gulbenkian, 2005 [1797], p. 236 [RL, AA 06: 236].

76 "Subsequently we can develop from the moral imperative, the concept of a right or power to impose legal obligation on others; but duty is the more fundamental concept" [GREGOR, Mary J. Law of Freedom: A Study of Kant's Method of Applying the Categorical Imperative in the 'Methapysik der Sitten'. Oxford: Blackwell, 1963, p. 45].

77 "But the notion of duty, as the matter of obligation, is so closely connected in our consciousness with ethical obligation that it is better to speak in / terms of rights rather than of duties, and so to remind ourselves that Law has nothing to do with virtue and its requirements. Law, as we have seen, has no concern with our moral disposition or attitude of will" [GREGOR, Mary J. Law of Freedom: A Study of Kant's Method of Applying the Categorical Imperative in the 'Methapysik der Sitten'. Oxford: Blackwell, 1963, p. 45-46].

78 "When the principle of Law commands that each subject of the law be left free to pursue his own ends, it is not at all concerned with what these ends may be or with whether the pursuit of them is morally good or bad. From its point of view, for example, the miser must be left free to pursue the thoroughly immoral ends of his avarice, so long as his actions 
Seja como for, o sistema deve ser pensado como um todo complexo que une obrigação, coerção e direito ${ }^{79}$. As três possibilidades estão conectadas, por isso, "Quer consideremos a jurisprudência como um sistema de direitos ou como um sistema de deveres jurídicos é indiferente em si, pois um dever jurídico é simplesmente uma ação que podemos ser legalmente obrigados a executar." 80 Melhor dito, trata-se de um sistema indiferente tanto aos motivos do que cumpre a lei, quanto com ou uso que cada um faz de sua liberdade quando ela não prejudica a liberdade dos outros fazerem o mesmo ${ }^{81}$.

Nesse particular, para Hobbes o conceito de direito é prioritário, não o de dever, como bem observa Habermas ${ }^{82}$.

\section{Ordem pública: coerência e incoerência em relação à obediência ao Estado injusto ou tirânico}

Um aspecto que clama por uma análise em relação à coerência diz respeito à concepção de Estado, especificamente sobre o que é permitido fazer quando o Estado não respeita os fundamentos, tais quais propostos por Hobbes e por Kant. Ou seja, o que se pode fazer quando o Estado não respeita os princípios a priori do direito público e o que se pode fazer quando o mesmo não respeita a finalidade que Hobbes comete a ele via lei natural.

Acima, foram apresentadas as argumentações de Kant e Hobbes para estabelecer o conceito de dever, de obrigação, ou seja, a lei moral e a lei

toward these ends do not violate the freedom of others. [...] he [legislator] guarantees the freedom of the miser to pursue his avarice through actions consistent with the freedom of others" [GREGOR, Mary J. Law of Freedom: A Study of Kant's Method of Applying the Categorical Imperative in the 'Methapysik der Sitten'. Oxford: Blackwell, 1963, p. 45-46].

79 "The moral title of others to compel us through the power of the State, their rights according to the law, are based upon our consciousness of obligation toward them, which is, in turn, based upon our recognition of the presence of pure practical reason within us and of our obligation toward our own personality" [GREGOR, Mary J. Law of Freedom: A Study of Kant's Method of Applying the Categorical Imperative in the 'Methapysik der Sitten'. Oxford: Blackwell, 1963, p. 46].

${ }^{80}$ GREGOR, Mary J. Law of Freedom: A Study of Kant's Method of Applying the Categorical Imperative in the 'Methapysik der Sitten'. Oxford: Blackwell, 1963, p. 45.

81 "Jurisprudence, in short, is concerned neither with the moral disposition of the subject whose actions it restrains nor with that of the subject whose rights it thereby determines. The one can obey the 1 aw merely from fear of its sanctions; the other can use his freedom to seek what ends he will, and the requirements of Law are thereby satisfied. Outer freedom is a strictly juridical concept having to do only with men's external actions. Their attitude of will is the object of laws of inner freedom, which is an exclusively ethical concept" [GREGOR, Mary J. Law of Freedom: A Study of Kant's Method of Applying the Categorical Imperative in the 'Methapysik der Sitten'. Oxford: Blackwell, 1963, p. 45-46].

${ }^{82}$ HABERMAS, Jürgen. The Inclusion of the Other: Studies in Political Theory. Cambridge: MIT Press, 1998, p. 191. 
natural, respectivamente. $\mathrm{O}$ passo seguinte consiste na transição da lei para a ação. Ou seja, trata-se de averiguar como tal lei opera para o ser humano, um ser racional sensível. Portanto, há um momento no pensamento das teorias morais em que deve ser pensada a conexão entre a lei e a ação humana. Deveras, eis a formulação de Kant que distingue a lei da motivação:

Toda legislação (prescreva ações internas ou externas, e essas, ou a priori, através da simples razão, ou através do arbítrio de um outro) contém duas partes: primeiro, uma lei, que representa objetivamente como necessária a ação que deve acontecer, i. e., que faz da ação um dever, segundo, um móbil [Triebfeder], que liga subjetivamente à representação da lei o fundamento de determinação do arbítrio para esta ação; a segunda parte é, pois, esta: que a lei faz do dever um móbil [dass Gesetz die Pflicht zur Triebfeder macht]. Pela primeira, a ação é representada como dever, o que é um mero conhecimento teórico [ein blosses theoretisches Erkenntnis] da determinação possível do arbítrio, i. e., de regras práticas; pela segunda, a obrigação de assim agir é ligada efetivamente no sujeito ao fundamento de determinação do arbítrio. ${ }^{83}$

Hobbes, também, distingue a obrigação e a motivação, o que pode ser percebido na sua distinção entre um homem justo e uma ação justa: "deve ser tido por injusto quem age corretamente só por medo ao castigo apenso à lei, e age injustamente já devido à iniquidade de sua mente." 84 De fato, na citação seguinte Hobbes distingue a lei e os motivos para o cumprimento da mesma:

“Também dissemos que as leis de natureza dizem respeito acima de tudo à consciência; isto é, que é justo aquele que se empenha na medida do possível para cumpri-las. Mas será injusto o homem que regular todas as suas ações segundo a obediência externa, tanto quanto a lei ordena, se ele assim agir não por causa da lei, mas devido a algum castigo anexado a esta, ou por vanglória. ${ }^{85}$

Nas palavras do comentador, "[...] ele [Hobbes] distingue explicitamente entre a obrigação de manter um contrato e qualquer motivo para fazê-lo." ${ }^{86}$

Pretende-se analisar as teorias de Kant e de Hobbes tomando por base essa hipótese de interpretação alavancada por Kant, a saber, aquela da distinção entre a lei e a motivação. No caso de Kant essa formulação é muito importante porque é ela que está na base da distinção entre uma

\footnotetext{
${ }^{83}$ KANT, Immanuel. A metafísica dos costumes. [Trad. J. Lamego]. Lisboa: Fundação Calouste Gulbenkian, 2005 [1797], p. 218 [RL, AA 06: 218].

${ }^{84}$ HOBBES, Thomas. Do cidadão. [R. J. Ribeiro: Philosophical Rudiments Concerning Government and Society]. 2. ed., São Paulo: Martins Fontes, 1998 [1642], 56, cap. III, §5.

${ }^{85}$ HOBBES, Thomas. Do cidadão. [R. J. Ribeiro: Philosophical Rudiments Concerning Government and Society]. 2. ed., São Paulo: Martins Fontes, 1998 [1642], 85-86, cap. IV, §21.

${ }^{86}$ DARWALL, Stephen. The British Moralists and the Internal 'Ought': 1640-1740. Cambridge: Cambridge University Press, 1995, p. 54.
} 
legislação ética e uma legislação jurídica. Tomar-se-á, como dito, o caso extremo do jus necessitatis, especificamente no direito público, como pedra de toque para avaliar a teoria e as consequências da motivação em ambos os autores. Nesse sentido, a análise do jus necessitatis dá ensejo para avaliar a coerência de Hobbes e a inconsistência de Kant com relação ao conceito de obrigação, ao menos sob esse viés.

Que Kant leve a sério, no direito, os conceitos de obrigação e de dano fica patente em razão da sua reiterada referência ao caso extremo. Pode-se afirmar que Kant vislumbrou o caso extremo como uma espécie de teste para a concepção de direito inflacionada moralmente. Segundo Williams o conceito de direito em Kant já nasce regrado, pois vem a lume fundido com o princípio universal do direito ${ }^{87}$.

O conceito de autonomia, no âmbito moral, nasce conectado com o conceito de lei moral, tanto que Allison a chamou de tese da reciprocidade entre liberdade e lei moral ${ }^{88}$. Na doutrina do direito, a liberdade é uma autorização, ou seja, ela já é algo filtrado, algo que passa pelo crivo de um critério e que, portanto, constitui-se no que pode resultar dele. Melhor dito, a liberdade sob o ponto de vista jurídico é aquela que não causa dano a ninguém. Uma tal liberdade, como visto, é, inclusive, deflacionada moralmente, ou seja, Kant concede que a sua justificação jurídica não comporta avaliação moral para além do que não causar prejuízo a terceiros. Se a ação não causar dano, o que para ele significa que respeita a mesma liberdade para os outros, então, ela será um direito, uma autorização, mesmo se imoral for. É acurado sustentar que desrespeitar os deveres para com os outros é equivalente a violar a liberdade dos outros ou é equivalente a lhes causar prejuízo, dano.

Como dito, Kant considerou muito importante o tratamento do jus necessitatis, pois ele se constitui em uma espécie de teste de sua teoria obrigacional. Com efeito, ele o trata tanto no texto Contra Hobbes, quanto no texto da Doutrina do direito. Em ambas as obras, Kant nega o chamado jus in casu necessitatis. Naquela obra, Kant sustenta que "conservar a minha vida é apenas um dever condicional (se tal puder ocorrer sem crime); mas é um dever incondicional não a tirar a outrem, que não me prejudica, e que nem sequer me põe em perigo de perder a minha." ${ }^{89}$. Nesta última obra

\footnotetext{
87 "Kant's image of liberty is therefore one not of unhindered or unrestricted motion, but rather of self-governed motion within publicly recognized and enforced limits. For Kant there is no human liberty without legal restraint" [WILLIAMS, Howard. Kant's Critique of Hobbes. Cardiff: University of Wales Press, 2003, p. 71].

${ }^{88}$ ALLISON, H. E. Kant's Theory of Freedom. New York: Cambridge University Press, 1990, p. 201 e seguintes.

${ }^{89}$ KANT, Immanuel. Sobre a expressão corrente: isso pode ser correcto na teoria, mas nada vale na prática. [Trad. Artur Morão]. Covilhã: Lusofia Press, s/d [1793]. [http://www.lusosofia.net/], p. 31-32 [TP, AA 08: 300 nota].
} 
ele afirma: "não pode haver necessidade que tornasse legal [gesetzmäßig] o que é injusto [unrecht]." ${ }^{\prime 0}$ No entanto, em ambas Kant concede que tais ações, embora culpáveis, não devem ser punidas, haja vista que a pena que o direito pode ofertar para ações em uma tal situação é sempre menor do que a perda que se poderia sofrer no estado de necessidade. De fato, em Contra Hobbes ele afirma:

os professores de direito civil geral procedem de modo inteiramente consequente ao conceder autorização jurídica a este socorro na necessidade. Pois a autoridade não pode ligar nenhum castigo à interdição, porque tal pena deveria ser a morte. Mas seria uma lei absurda ameaçar com a morte alguém que, em circunstâncias perigosas, não se entregasse de bom grado à morte. ${ }^{91}$

Como se verá, Kant não aceita o argumento do estado de necessidade como fundamento para a desobediência ao Estado injusto, contudo, feita a revolução, não caberia punição aos vitoriosos. A contrarrevolução é vedada por Kant:

Se também pela violência de uma revolução, gerada por uma má constituição, se tivesse conseguido de um modo ilegítimo uma constituição mais conforme à lei, não se deveria já considerar lícito reconduzir o povo novamente à antiga constituição, embora durante a vigência desta quem tenha perturbado a ordem com violência ou astúcia ficasse justamente submetido às sanções do rebelde. ${ }^{92}$

No caso de Hobbes, segue-se um posicionamento bem diferente, haja vista os fundamentos de sua teoria. Para ele, medo e liberdade são compatíveis, bem como liberdade e necessidade.$^{93}$ Nesse particular, a teoria de Hobbes já nasce conexa com uma formulação da natureza humana. Para ele, há uma relação analítica entre o fim real que deve ser pressuposto, qual seja a

\footnotetext{
${ }^{90}$ KANT, Immanuel. A metafísica dos costumes. [Trad. J. Lamego]. Lisboa: Fundação Calouste Gulbenkian, 2005 [1797], p. 236 [MS, AA 06: 236].

${ }^{91}$ KANT, Immanuel. Sobre a expressão corrente: isso pode ser correcto na teoria, mas nada vale na prática. [Trad. Artur Morão]. Covilhã: Lusofia Press, s/d [1793]. [http://www.lusosofia.net/], p. 31-32 [TP, AA 08: 300 nota].

${ }^{92}$ KANT, Immanuel. A paz perpétua: um projeto filosófico. [Trad. Artur Morão]. Covilhã: Lusofia Press, 2008 [1795]. [http://www.lusosofia.net/], p. 37 [VAZeF, AA 08: 372-373].

93 "Feare, and Liberty are consistent; as when a man throweth his goods into the Sea for feare the ship should sink, he doth it neverthelesse very willingly, and may refuse to doe it if he will: It is therefore the action, of one that was free: so a man sometimes pays his debt, only for feare of Imprisonment, which because no body hindred him from detaining, was the action of a man at liberty. And generally all actions which men doe in Commonwealths, for feare of the law, are actions, which the doers had liberty to omit. Liberty, and Necessity are consistent: As in the water, that hath not only liberty, but a necessity of descending by the Channel; so likewise in the Actions which men voluntarily doe: which, because they proceed from their will, proceed from liberty; and yet, because every act of mans will, and every desire, and inclination proceedeth from some cause, and that from another cause, in a continuall chaine, (whose first link is in the hand of God the first of all causes,) they proceed from necessity." [HOBBES, Thomas. Leviathan, or Matter, Form, and Power of a Commonwealth Ecclesiastical and Civil. [Edited by C.B. Macpherson]. London: Penguin, 1968 [1651], chap. XXI].
} 
autoconservação, e os meios para tal, a saber, as leis naturais. Certamente, a motivação para o cumprimento da lei depende precipuamente de que tal fim seja o fim do agente e depende também da expectativa de que outros tenham o mesmo fim e igualmente cumpram as leis naturais. Para Hobbes, o contrato que cria obrigações é um ato voluntário e como todo ato voluntário ele tem um bem em vista para aquele que firma o contrato: "Pois é um ato voluntário, e o objetivo de todos os atos voluntários dos homens é algum bem para si mesmos." ${ }^{\prime 94}$ A deliberação para contratar, como toda deliberação em geral, terá um apetite ou uma aversão naturais do homem como sua base: "Na deliberação, o último apetite ou aversão imediatamente anterior à ação ou à omissão desta é o que se chama vontade, o ato (não a faculdade) de querer." ${ }^{\prime 95}$ Destarte, ainda que os domínios da ética e da justiça sejam distintos em Hobbes, haja vista aquela remeter à paixões e esta à linguagem mediante a qual se torna possível o ato contratual, há um ponto em que ambas se conectam, justamente o âmbito da motivação ${ }^{96}$. A lei é um comando para a autopreservação. A obrigação nasce de um ato contratual que renuncia direitos para dar eficácia, tornar exigível tal lei. A resposta à motivação para cumprir a obrigação depende de se querer ou ter o fim da autopreservação. A explicação da motivação conecta a teoria da obrigação, a teoria da justiça, com a teoria da natureza humana, com a teoria das paixões e, por extensão, com os conceitos de bem e de mal, especialmente com a noção de o maior dos males, a dor da morte violenta.

Nessa perspectiva, segundo Hobbes, os movimentos voluntários advêm de pequenos movimentos interiores: "Estes pequenos inícios do movimento, no interior do corpo do homem, antes de se manifestarem no andar, na fala, na luta e outras ações visíveis, chamam-se geralmente esforço." ${ }^{\prime 97}$ Apetites e aversões são movimentos nos órgãos internos: "Este esforço, quando vai em direção de algo que o causa, chama-se apetite ou desejo, sendo o segundo o nome mais geral, e o primeiro frequentemente limitado a significar o desejo de alimento, nomeadamente a fome e a sede. Quando o esforço vai no sentido de evitar alguma coisa chama-se geralmente aversão." ${ }^{\prime 98}$ Essa é

\footnotetext{
${ }^{94}$ HOBBES, Thomas. Leviatã ou matéria, forma e poder de um estado eclesiástico e civil. [Trad. J. P. Monteiro e M.B.N. da Silva: Leviathan, or Matter, Form, and Power of a Commonwealth Ecclesiastical and Civil]. 2. ed., São Paulo: Abril Cultural, 1983 [1651], cap. XIV.

${ }^{95}$ HOBBES, Thomas. Leviatã ou matéria, forma e poder de um estado eclesiástico e civil. [Trad. J. P. Monteiro e M.B.N. da Silva: Leviathan, or Matter, Form, and Power of a Commonwealth Ecclesiastical and Civil]. 2. ed., São Paulo: Abril Cultural, 1983 [1651], cap. VI.

96 "Although the decision to enter into a covenant is based on our passions (an appetite to enter the covenant and to receive whatever benefits we expect from it), what obliges us to keep our covenants follows from the words of covenant" [PEACOCK, Mark. Obligation and Advantage in Hobbes' Leviathan. Canadian Journal of Philosophy. V. 40, n. 3, 2010, p. 438].

${ }^{97}$ HOBBES, Thomas. Leviatã ou matéria, forma e poder de um estado eclesiástico e civil. [Trad. J. P. Monteiro e M.B.N. da Silva: Leviathan, or Matter, Form, and Power of a Commonwealth Ecclesiastical and Civil]. 2. ed., São Paulo: Abril Cultural, 1983 [1651], cap. VI.

${ }_{98}^{98}$ HOBBES, Thomas. Leviatã ou matéria, forma e poder de um estado eclesiástico e civil. [Trad. J. P. Monteiro e M.B.N. da Silva: Leviathan, or Matter, Form, and Power of a Commonwealth Ecclesiastical and Civil]. 2. ed., São Paulo: Abril Cultural, 1983 [1651], cap. VI.
} 
base na qual Hobbes alicerça os conceitos de bem e mal: "Mas seja qual for o objeto do apetite ou desejo de qualquer homem, esse objeto é aquele a que cada um chama bom; ao objeto de seu ódio e aversão chama mau"99.

Com base nesta passagem, e em outras do Leviathan, Darwall fundamenta o que ele chama de projetivismo [projectivism] com relação à concepção de bem. ${ }^{100}$ Deveras, no caso da citação em comento, Darwall chama a atenção para a importância do temo called. Segundo sua interpretação, Hobbes não estaria a dizer que bom e mau significam o que desejamos ou que evitamos, não, "Ele diz que aquilo que desejamos chamamos de bom. [...] Quando alguém chama algo de bom, ele expressa seu desejo. Ele não diz que deseja aquilo"101. Ou seja, o falante estaria a expressar o seu desejo daquilo, não que de fato deseja aquilo. Como afirma Hobbes, "O bem e o mal são nomes que significam nossos apetites e aversões"102. Eles não são nomes para o que de fato desejamos ou evitamos. Desse modo, Darwall pensa poder evitar o subjetivismo que decorreria da sustentação de que as leis naturais dependeriam de o sujeito ter o desejo da autoconservação.

Ademais, em relação à tese do projetivismo, o que existe na realidade são os pequenos movimentos nos órgãos interiores, os quais são sentidos pelo sujeito de uma determinada forma, ou seja, esses movimentos aparecem sob uma determinada forma para o sujeito que tem sensações. ${ }^{103}$ Dito nos termos de Dawall, são projeções de valores.

\footnotetext{
${ }^{99}$ HOBBES, Thomas. Leviatã ou matéria, forma e poder de um estado eclesiástico e civil. [Trad. J. P. Monteiro e M.B.N. da Silva: Leviathan, or Matter, Form, and Power of a Commonwealth Ecclesiastical and Civil]. 2. ed., São Paulo: Abril Cultural, 1983 [1651], cap. VI.

${ }^{100}$ DARWALL, Stephen. Normativity and Projection in Hobbes's Leviathan. The Philosophical Review. V. 109, n. 3, 2000, p. 318. Com essa tese, ele diz desafiar a interpretação de vários comentadores, tais como Gauthier, Hampton e Kavka [DARWALL, Stephen. Normativity and Projection in Hobbes's Leviathan. The Philosophical Review. V. 109, n. 3, 2000, p. 315]. 101 "He says that what we desire we call good. [...] When someone calls something good, he expresses his desire. He does not say that he desires it" [DARWALL, Stephen. Normativity and Projection in Hobbes's Leviathan. The Philosophical Review. V. 109, n. 3, 2000, p. 327].

${ }^{102}$ HOBBES, Thomas. Leviatã ou matéria, forma e poder de um estado eclesiástico e civil. [Trad. J. P. Monteiro e M.B.N. da Silva: Leviathan, or Matter, Form, and Power of a Commonwealth Ecclesiastical and Civil]. 2. ed., São Paulo: Abril Cultural, 1983 [1651], cap. XV.

103 "As, in Sense, that which is really within us, is (as I have sayd before) onely Motion, caused by the action of externall objects, but in apparence; to the Sight, Light and Colour; to the Eare, Sound; to the Nostrill, Odour, \&c: so, when the action of the same object is continued from the Eyes, Eares, and other organs to the Heart; the reall effect there is nothing but Motion, or Endeavour; which consisteth in Appetite, or Aversion, to, or from the object moving. But the apparence, or sense of that motion, is that wee either call DELIGHT, or TROUBLE OF MIND. [...] Pleasure therefore, (or Delight,) is the apparence, or sense of Good; and Molestation or Displeasure, the apparence, or sense of Evill. And consequently all Appetite, Desire, and Love, is accompanied with some Delight more or lesse; and all Hatred, and Aversion, with more or lesse Displeasure and Offence. [...] Pleasure therefore, (or Delight, ) is the apparence, or sense of Good; and Molestation or Displeasure, the apparence, or sense of Evill." [HOBBES, Thomas. Leviathan, or Matter, Form, and Power of a Commonwealth Ecclesiastical and Civil. [Edited by C.B. Macpherson]. London: Penguin, 1968 [1651], chap. VI].
} 
É de acordo com essa estrutura conceitual da obrigação apresentada por ambos os autores que se deve entender as suas afirmações sobre as obrigações políticas. Assim, Kant afirma que a união civil é um fim em si mesma. Essa afirmação pode ser interpretada ao menos de dois modos.

A primeira é a de que só seria fim em si aquele Estado que determinasse e garantisse a cada um o que é seu, haja vista ao Estado ser cometido "determinar a cada um [jedem das Seine] o que é seu e garanti-lo" ${ }^{104}$ Cada um deveria, então, significar todos, como afirma o segundo parágrafo do texto Contra Hobbes, ou seja, teria que haver uma concordância da "liberdade de cada um [Freiheit eines jeden]" com "a liberdade de todos [Freiheit von jedermann]", ${ }^{105}$ o que só seria possível segundo uma lei universal. Com efeito, a palavra jedes ou jedem, cada um, todos, aparece também no terceiro parágrafo quando Kant declina os três princípios a priori de um estado jurídico ou civil [rechtlicher Zustand]: ${ }^{106}$

"1. A liberdade de cada [jedes] membro da sociedade, como homem;

2. A igualdade deste com todos [jedem] os outros, como súdito.

3. A independência de cada [jedes] membro de uma comunidade, como cidadão." 107

Desse modo, só seria um fim em si aquele Estado que obedecesse a esses ditames.

A segunda possibilidade é que qualquer Estado é um fim em si, mesmo um Estado injusto.

Kant parece aderir a essa segunda hipótese, pois, em Contra Hobbes, ele defende uma proibição incondicional de qualquer reação a qualquer Estado,

${ }^{104}$ KANT, Immanuel. Sobre a expressão corrente: isso pode ser correcto na teoria, mas nada vale na prática. [Trad. Artur Morão]. Covilhã: Lusofia Press, s/d [1793]. [http://www.lusosofia.net/], p. 19 [TP, AA 08: 289].

${ }^{105}$ KANT, Immanuel. Sobre a expressão corrente: isso pode ser correcto na teoria, mas nada vale na prática. [Trad. Artur Morão]. Covilhã: Lusofia Press, s/d [1793]. [http://www.lusosofia.net/], p. 20 [TP, AA 08: 289-290].

${ }^{106}$ Em uma longa nota de tradução à Metafísica dos costumes Gregor anotou que o termo Recht é de difícil tradução, bem como os adjetivos que se derivam dele, como rechtlich. $\mathrm{O}$ termo tem inclusive o sentido de justo, gerecht [GREGOR, Mary. Translator's Note on the text of The metaphysics of Morals. In KANT, Immanuel. Practical philosophy. [Transl. Mary Gregor]. [The Cambridge Edition of The Works of Immanuel Kant]. Cambridge: Cambridge University Press, 1996, p. 355-359]. No presente caso, poder-se-ia pensar em uma relação com um sistema justo. Byrd e Hruschka são mais incisivos: "Kant uses the adjectives 'right' (recht) for the lex iusti and 'juridical' (rechtlich) for the lex iuridica." [BYRD, B. Sharon, HRUSCHKA, Joachim. Kant's 'Doctrine of Right': A Commentary. Cambridge: Cambridge University Press, 2010, p. 52]. Eles chamam a atenção para a p. 306 da RL na qual Kant relacionada o adjetivo rechtlich à lex iuridica.

${ }^{107}$ KANT, Immanuel. Sobre a expressão corrente: isso pode ser correcto na teoria, mas nada vale na prática. [Trad. Artur Morão]. Covilhã: Lusofia Press, s/d [1793]. [http://www.lusosofia.net/], p. 20 [TP, AA 08: 290]. 
mesmo que ele seja tirânico, ${ }^{108}$ exceção feita à crítica pública do mesmo. Na Doutrina do direito ele sustenta que o povo tem o dever "de suportar mesmo um abuso do poder supremo considerado insuportável"109. Na Paz perpétua, afirma:

São leis permissivas da razão conservar a situação de um direito público, viciado pela injustiça, até por si mesma estar madura para uma transformação plena ou se aproximar da sua maturação por meios pacíficos; pois qualquer constituição jurídica, embora só em grau mínimo seja conforme ao direito, é melhor do que nenhuma; uma reforma precipitada depararia com o seu último destino (a anarquia). ${ }^{110}$

A posição kantiana é estreme de dúvidas a esse respeito, pois ele extirpa a desobediência até no caso extremo que a justificaria, ou seja, no ius in casu necessitatis: "Também aqui não pode interferir um direito de necessidade (ius in casu necessitatis) que, de qualquer modo, enquanto pretenso direito de cometer uma infracção ao direito na extrema indigência (física), é um contra-senso, mesmo que forneça a chave para levantar a barreira que limita o poder próprio do povo."111 Nesse sentido, "A necessidade não poderia criar direitos nem obrigar se as ações governadas pela necessidade fossem somente respostas naturais das criaturas a forças naturais." ${ }^{112} \mathrm{O}$ verso da medalha de um fim da razão é um dever incondicional de obediência, muito embora ele não deixe de registrar que o dever de reformar o Estado para melhor conta com o bom incentivo de que a natureza por si mesma pode suscitar uma revolução:

A sabedoria política, no estado em que as coisas agora estão, converterá num dever a realização de reformas adequadas ao ideal do direito público: utilizará, porém, as revoluções, onde a natureza por si mesma as suscita, não para desculpar uma opressão ainda maior, mas como apelo da natureza a instaurar, por meio de reformas profundas, uma constituição legal fundada nos princípios da liberdade, como a única constituição permanente. ${ }^{113}$

Kant considera que a ideia do contrato originário, traduzida pelos princípios a priori do direito que ele formula, são como uma bitola infalível

\footnotetext{
${ }^{108}$ KANT, Immanuel. Sobre a expressão corrente: isso pode ser correcto na teoria, mas nada vale na prática. [Trad. Artur Morão]. Covilhã: Lusofia Press, s/d [1793]. [http://www.lusosofia.net/], p. 31-32 [TP, AA 08: 299-300].

${ }^{109}$ KANT, Immanuel. A metafísica dos costumes. [Tr. J. Lamego]. Lisboa: Fundação Calouste Gulbenkian, 2005 [1797], p. 320 [RL, AA 06: 320].

${ }^{110}$ KANT, Immanuel. A paz perpétua: um projeto filosófico. [Trad. Artur Morão]. Covilhã: Lusofia Press, 2008 [1795]. [http://www.lusosofia.net/], p. 37 [VAZeF, AA 08: 374 nota].

${ }^{111}$ KANT, Immanuel. Sobre a expressão corrente: isso pode ser correcto na teoria, mas nada vale na prática. [Trad. Artur Morão]. Covilhã: Lusofia Press, s/d [1793]. [http://www.lusosofia.net/], p. 31-32 [TP, AA 08: 300].

112 "Necessity can neither create rights nor obligate if only because actions governed by necessity are the natural responses of creatures to natural forces" [HERBERT, Gary B. Kant Contra Hobbes. Hobbes Studies. V. 17, n. 1, 2004].

${ }^{113}$ KANT, Immanuel. A paz perpétua: um projeto filosófico. [Trad. Artur Morão]. Covilhã: Lusofia Press, 2008 [1795]. [http://www.lusosofia.net/], p. 37 [VAZeF, AA 08: 374 nota].
} 
para o julgamento que visa a determinar se uma norma se conforma ou não à justiça do direito público:

na apreciação de se foi com prudência que se tomou, ou não, determinada medida, o legislador pode decerto enganar-se, mas não quando ele se interroga sobre se a lei se harmoniza, ou não, também com o princípio do direito; pois então dispõe, claro está, a priori como que de uma bitola infalível [unfehlbaren Richtmaße] da ideia do contrato originário (e não precisa, como no princípio da felicidade, de esperar por experiências que tenham primeiro de o aconselhar acerca da conveniência dos seus meios). De facto, contanto que não haja contradição em que um povo inteiro dê por voto o seu assentimento a uma tal lei, por muito penoso que lhe seja aceitá-la, esta lei é conforme ao direito ${ }^{114}$.

Ainda assim, ao final, "numa constituição civil já existente, o povo já não tem por direito a decisão de determinar como é que ela deve ser administrada. Pois, supondo que ele tem esse direito e, claro está, o direito de se opor à decisão do efetivo chefe de Estado, quem decidirá de que lado está o direito"? ${ }^{115}$ Como se percebe, isso não tem maiores consequências, a não ser a possibilidade da crítica pública, pois não tem incidência sobre a possibilidade ou não de desobedecer ao soberano, diferentemente de Hobbes, como se verá a seguir. A bitola mencionada por Kant é operada pelo soberano. $\mathrm{O}$ súdito pode manejá-la apenas para efeito de crítica ao soberano e apelo para que reforme a lei. Como anota o comentador, " [...] ele [Kant] propõe um soberano contra o qual os cidadãos não retêm direitos coercitivos, nem mesmo o direito à vida. Kant apresenta isso como uma crítica a Hobbes"116.

Já, a posição de Hobbes é bem diferente. Hobbes reformula a liberdade redefinindo-a de uma concepção da mesma como não-dominação para uma formulação como não-interferência, de tal forma que ela se torna virtualmente compatível com qualquer forma de governo, ${ }^{117}$ exceto a escravidão. Pettit epiteta tal redefinição do conceito de liberdade como um trabalho desonesto (rigged job). ${ }^{118}$ Da mesma forma, ele reformula a lei natural de

\footnotetext{
${ }^{114}$ KANT, Immanuel. Sobre a expressão corrente: isso pode ser correcto na teoria, mas nada vale na prática. [Trad. Artur Morão]. Covilhã: Lusofia Press, s/d [1793]. [http://www.lusosofia.net/], p. 30 [TP, AA 08: 299].

${ }^{115}$ KANT, Immanuel. Sobre a expressão corrente: isso pode ser correcto na teoria, mas nada vale na prática. [Trad. Artur Morão]. Covilhã: Lusofia Press. [Disponível em: http://www.lusosofia. net/], p. 31-32 [TP, AA 08: 299-300]. WALDRON, Jeremy. Kant's Legal Positivism. Harvard Law Review. N. 109, 1995-1996, p. 1535-1566.

${ }_{116}$ HERBERT, Gary B. Kant Contra Hobbes. Hobbes Studies. V. 17, n. 1, 2004, p. 23.

117 "There is a sense, therefore, in which all political power, however derived, is based upon the choice and consent of the patient, in that the source of that power is always his own will. It is in virtue of this consideration that Hobbes is able to maintain that all forms of government are ultimately democratic" [WARRENDER, Howard. The Political Philosophy of Hobbes. Oxford: Oxford University Press, 1957, p. 313].

118 "The shift that Hobbes consciously made in his thinking about liberty looks, in retrospect, to have been a rigged job. He did not give any credence to the received notion of the free citizen: the person protected with and against others, under a republic of nonarbitrary law.
} 
tal forma que gera o oposto do que a tradição costumava lhe atribuir. De uma normatividade alternativa àquela do soberano, a lei natural passa a fundamentar a própria autoridade absoluta do soberano, tanto que Slomp nomeia de perversa tal reformulação ${ }^{119}$. Esta é a razão pela qual alguns autores comprometem Hobbes com o positivismo jurídico ${ }^{120}$, como é o caso de Hart, ${ }^{121}$ Hampton $^{122}$ e Heck $^{123}$.

$\mathrm{O}$ argumento contra o louco mostra a força e o limite do vínculo obrigacional. A sua força está em que o pacto tem que ser cumprido no interesse da autopreservação. Porém, o seu limite está em que nunca será no melhor autointeresse abandonar a autodefesa, o que implicará o direito de resis$\operatorname{tir}^{124}$ quando a existência mesma do sujeito estiver em perigo. Como bem apontou Kavka, a racionalidade indica meios diferentes de sobrevivência em razão da finalidade em conjunção com as circunstâncias. ${ }^{125}$

Rather he took the word "freedom" and, sensitive to the demands of his political ontology, gave it a content that would allow the best possible gloss on the absolutist regime he recommended. The free person ceases to be someone with a secure status in relation to power-no one has such a standing before the sovereign-and is recast, in the words from Leviathan, as the person who happens not to be obstructed in the pursuit of those things "he has a will to' do among actions that by 'his wit and strength he is able to do.'" [PETTIT, Philip. Made with Words: Hobbes on Language, Mind, and Politics. Princeton and Oxford: Princeton University Press, 2008, p. 140].

119 " $[\ldots]$ there is nothing perverse about the content of Hobbes's laws of nature. However, if we now look at their function, their perversity begins to emerge. On the surface Hobbes offers a definition of the law of nature which does not differ formally from traditional definitions. For Hobbes, the law of nature is a dictate of right reason. [...] Whereas for other natural-law theorists recta ratio prescribes what is good or evil in itself, for Hobbes instead reason indicates what is good or bad in relation to a given end. [...] Unlike the traditional law of nature, Hobbes's natural law is not a code of behaviour valid without and above positive law; its function is to provide a rational foundation for the system of positive law." [SLOMP, Gabriella. Kant against Hobbes: Reasoning and Rhetoric. Journal of Moral Philosophy. V. 4, n. 2, 2007, p. 215-216].

${ }^{120}$ DUKE, George. Hobbes on Political Authority, Practical Reason and Truth. Law and Philosophy. V. 33, 2014, p. 607.

${ }^{121}$ HART, H. L. A. The Concept of Law. 2. ed., Oxford: Clarendon Press, 1994 [1961], p. 63

${ }^{122}$ HAMPTON, Jean. Hobbes and the Social Contract Tradition. Cambridge: Cambridge University Press, 1986, p. 244.

123 "Por mais absolutista que a teoria do legalismo positivista hobbesiano seja, ela não absorve a liberdade natural como fonte do direito. Para o teórico político inglês, nenhum homem pode ser obrigado a se matar, a ser proibido de defender a integridade física e de eliminar quem atenta contra a sua vida, a ser forçado a confessar um crime sem garantias de perdão ou a cumprir ordens que impliquem alto risco ou desabonem a sua honra. Hobbes não integra o direito na lei e nem ajusta a lei ao direito, de modo que à liberdade natural dos súditos não corresponde lacuna legal nos comandos do soberano" [HECK, José N. Thomas Hobbes : passado e futuro. Goiânia: EdUFG, 2004, p. 135-6].

124 "Hobbes uses the term right with two distinct meanings: (1) as that to which one is morally entitled; (2) as that which one cannot be obliged to renounce." [WARRENDER, Howard. The Political Philosophy of Hobbes. Oxford: Oxford University Press, 1957, p. 18]. Ver VOLPATO DUTRA, Delamar José. Um homem não pode renunciar ao direito de resistir a quem o ataque pela força": a liberdade de desobedecer e o direito de resistir ao soberano segundo Hobbes. Sintese. V. 43, p. 5-38, 2016.

${ }^{125}$ KAVKA, Gregor. The Rationality of Rule-Following: Hobbes' Dispute with the Foole. Law and Philosophy. V. 14, 1995, p. 23. 
Ainda que tenha reformulado a lei natural para determinar a obediência ao soberano, Hobbes sustenta o direito de o súdito desobedecer ao soberano $^{126}$. Desse modo, "O Estado se constitui assim por meio de uma relação de mútua dependência entre direito e poder." 127 Fica claro, desse modo, o teorema básico da correlação entre proteção e obediência ${ }^{128}$. Veja-se que a capacidade de proteção não é referida por Hobbes à autoridade, mas ao poder, em contraposição ao direito de autoproteção. Como bem entendeu Schmitt, "O protego ergo obligo é o cogito ergo sum do Estado"129. Ou seja, o que importa realmente é a proteção ${ }^{130}$.

Esses motivos são suficientemente fortes para dar causa e manter o contrato nos termos do protego ergo obligo. Strauss, quando analisou a tese schmittiana de que o político se define pela "prontidão para morte"131, afirmou que Hobbes qualifica essa tese para salvaguardar exatamente a autopreservação:

O Estado pode justificadamente exigir do indivíduo apenas obediência condicional, a saber, uma obediência que não se opõe à salvação ou preservação da vida desse indivíduo; pois garantir a vida é a base última do Estado. Portanto, embora o homem seja obrigado a uma obediência incondicional, ele não tem obrigação de arriscar sua vida; pois a morte é o maior mal. Hobbes não evita a consequência e nega expressamente o status da coragem como virtude. ${ }^{132}$

Nesse mesmo diapasão, Warrender defende que em Hobbes operariam dois conceitos de direito, um como pretensão moral contra os outros e outro como não ser obrigado a renunciar:

\footnotetext{
126 "The Obligation of Subjects to the Soveraign, is understood to last as long, and no longer, than the power lasteth, by which he is able to protect them. For the right men have by Nature to protect themselves, when none else can protect them, can by no Covenant be relinquished. [...] The end of Obedience is Protection" [HOBBES, Thomas. Leviathan, or Matter, Form, and Power of a Commonwealth Ecclesiastical and Civil. [Edited by C.B. Macpherson]. London: Penguin, 1968 [1651], chap. XXI].

${ }^{127}$ LIMONGI, Maria Isabel. Direito e Poder: Hobbes e a dissolução do Estado. Dois Pontos. V. 6, n. 3, 2009, p. 84.

128 "And thus I have brought to an end my Discourse of Civill and Ecclesiasticall Government, occasioned by the disorders of the present time, without partiality, without application, and without other designe, than to set before mens eyes the mutuall Relation between Protection and Obedience" [HOBBES, Thomas. Leviathan, or Matter, Form, and Power of a Commonwealth Ecclesiastical and Civil. [Edited by C.B. Macpherson]. London: Penguin, 1968 [1651], parágrafo final].

${ }^{129}$ SCHMITT, Carl. O conceito do político. [Trad. Álvaro L. M. Valls: Der Begriff des Politischen]. Petrópolis: Vozes, 1992 [1932], p. 78.

${ }^{130}$ SCHMITT, Carl. El Leviathan en la teoría del estado de Tomas Hobbes. [Trad. F. J. Conde]. Granada: Comares, 2004 [1938], p. 28-29.

${ }^{131}$ SCHMITT, Carl. O conceito do político. [Trad. Álvaro L. M. Valls: Der Begriff des Politischen]. Petrópolis: Vozes, 1992, p. 75.

132 STRAUSS, Leo. Notes on Carl Schmitt "The Concept of the Political". [Trans. by J. Harvey Lomax: Anmerkungen zu Carl Schmitt [1932]]. In SCHMITT, Carl The Concept of the Political. [Trans. George Schwab]. Chicago: University of Chicago Press, 2007, p. 91, §13.
} 
"Hobbes usa o termo direito com dois significados distintos: (1) como aquilo a que se tem título moral; (2) como aquilo que não se pode obrigar a renunciar." 133 No primeiro caso, os direitos são o verso da medalha de deveres, são sombras de deveres. No segundo caso, os direitos são uma antítese dos deveres, ou seja, uma liberdade ou isenção de obrigação ${ }^{134}$. Quando Hobbes fala das verdadeiras liberdades dos súditos ou do direito a todos as coisas, a referência seria ao direito como isenção de obrigação ${ }^{135}$. Com efeito, ao se referir ao direito do súdito contra a punição do Estado ele anota "[...] ninguém é obrigado a não lhe resistir"136.

Portanto, uma característica desses direitos é que eles não constituem uma pretensão contra os outros. Foi por isso que Hobbes pôde afirmar, sem incoerência, que alguém tem direito à autopreservação e que os outros têm direito de matá-lo, pois o seu direito não implica em uma obrigação por parte dos demais. Um significado preciso disso é que, por exemplo, o indivíduo não pode ser obrigado a renunciar à sua vida ${ }^{137}$. A consequência que se segue é que o dever de não matar não pode ser derivado do direito à vida de alguém. $\mathrm{O}$ dever de não matar tem que ser derivado de outra fonte, por exemplo, da lei civil ou da lei natural. Segue-se disso, também, que o soberano pode matar o súdito e este pode resistir ao soberano, sem que nenhum dos dois cometa injustiça, porque o direito que está em questão é aquele no sentido de uma isenção de obrigação. Nenhum dos dois está obrigado a renunciar ao direito que pretende $\mathrm{e}^{38}$.

${ }^{133}$ WARRENDER, Howard. The Political Philosophy of Hobbes. Oxford: Oxford University Press, 1957, p. 18.

${ }_{134}$ WARRENDER, Howard. The Political Philosophy of Hobbes. Oxford: Oxford University Press, 1957, p. 19.

${ }_{135}$ WARRENDER, Howard. The Political Philosophy of Hobbes. Oxford: Oxford University Press, 1957, p. 20.

${ }^{136}$ HOBBES, Thomas. Leviatã ou matéria, forma e poder de um estado eclesiástico e civil. [Trad. J. P. Monteiro e M.B.N. da Silva: Leviathan, or Matter, Form, and Power of a Commonwealth Ecclesiastical and Civil]. 2. ed., São Paulo: Abril Cultural, 1983 [1651], cap. XIV.

137 WARRENDER, Howard. The Political Philosophy of Hobbes. Oxford: Oxford University Press, 1957, p. 20.

138 "It is with this meaning that Hobbes speaks of the 'true liberties' of the subject, which, as we shall see, are concerned with those things that the citizen cannot be obliged to do. It is also the type of right exemplified by the so-called 'right to all things' in the Hobbesian State of Nature. [...] Likewise, a right to life or to self-preservation, in Hobbes's doctrine, does not signify that the individual is entitled to life, in the sense that other men or the sovereign have a duty to spare him; it signifies that the individual cannot be obliged to renounce his life and so it is always consistent with duty for him to resist or escape attempts upon his life. But with this provision, such a right is exhausted, and if, for example, fellow citizens have a duty to refrain from killing the individual, this will derive from the civil law, forbidding murder, or from another source, and not from his right to life. Likewise, the sovereign may attempt to put a subject to death and the subject may resist violently, and both sovereign and subject be completely justified. These are typical situations in Hobbes's philosophy." [WARRENDER, Howard. The Political Philosophy of Hobbes. Oxford: Oxford University Press, 1957, p. 20]. "The duties-formula, moreover, gives also the limitations of these rights or entitlements of the sovereign. The subject may still be justified in running away from the 
Essa terminologia que Warrender utiliza relembra uma distinção estabelecida por Hohfeld, muito embora Warrender não o cite. Segundo Hohfeld, um direito como pretensão [claim] é o correlato de um dever dos outros ${ }^{139}$. Por seu turno, um direito como liberdade não implicaria essa correlação do direito com o dever de um outro ${ }^{140}$.

\section{Conclusão}

Em suma, nos termos do cap. XIV combinado com o XXI, ambos do Leviathan, o súdito tem a liberdade de desobedecer ao soberano naquelas coisas sem as quais ele não pode viver. Ora, justamente no cap. XIV Hobbes define o direito natural como a liberdade de usar do seu poder para a sua própria conservação, logo, trata-se de um legítimo direito natural. ${ }^{141}$

O Estado porta o poder decisório nos termos do cap. XXVI do Leviathan, pois a lei é carente de interpretação. Como se pode ler no De Cive, "O roubo, o assassínio e todas as injúrias são proibidos pela lei de natureza; mas o que há de se chamar roubo, o que assassínio, adultério ou injúria a um cidadão não se determinará pela lei natural, porém pela civil"142. Porém, o indivíduo mantém uma reserva para desobedecer, cuja matriz finca raiz na teoria mesma que embasa os conceitos de bem e de mal.

O súdito tem que abdicar de seus juízos privados, porém, não ao ponto em que exige Rousseau, pois o súdito não abdica da sua fé [Faith] e não abdica

battle line when he is hard pressed, and the entitlements of the sovereign exist no longer when he has lost the power to protect the citizen" [WARRENDER, Howard. The Political Philosophy of Hobbes. Oxford: Oxford University Press, 1957, p. 188].

139 "In other words, if $X$ has a right against $Y$ that he shall stay off the former's land, the correlative (and equivalent) is that $\mathrm{Y}$ is under a duty toward $\mathrm{X}$ to stay off the place. If, as seems desirable, we should seek a synonym for the term 'right' in this limited and proper meaning, perhaps the word 'claim' would prove the best" [HOHFELD, Wesley Newcomb. Some Fundamental Legal Conceptions as Applied in Judicial Reasoning. The Yale Law Journal. V. 23, n. 1, 1913, p. 32. Ver também HOHFELD, Wesley Newcomb. Faulty Analysis in Easement and License Cases. The Yale Law Journal. V. 27, n. 1, 1917, p. 71].

140 "A 'liberty' considered as a legal relation (or 'right' in the loose and generic sense of that term) must mean, if it have any definite content at all, precisely the same thing as privilege [...] It is equally clear, as already indicated, that such a privilege or liberty to deal with others at will might very conceivably exist without any peculiar concomitant rights against 'third parties' as regards certain kinds of interference" [HOHFELD, Wesley Newcomb. Some Fundamental Legal Conceptions as Applied in Judicial Reasoning. The Yale Law Journal. V. 23, n. 1, 1913, p. 36. Ver também HOHFELD, Wesley Newcomb. Faulty Analysis in Easement and License Cases. The Yale Law Journal. V. 27, n. 1, 1917, p. 69.

141 "Hobbes uses the term right with two distinct meanings: (1) as that to which one is morally entitled; (2) as that which one cannot be obliged to renounce." [WARRENDER, Howard. The Political Philosophy of Hobbes. Oxford: Oxford University Press, 1957, p. 18].

${ }^{142}$ HOBBES, Thomas. Do cidadão. [R. J. Ribeiro: Philosophical Rudiments Concerning Government and Society]. 2. ed., São Paulo: Martins Fontes, 1998 [1642], chap. VI, §16. 
de sua própria defesa. Em suma, "o individualismo de Hobbes é muito forte para permitir mesmo o mais breve aparecimento de algo semelhante à vontade geral."143 Parece que o súdito, em Hobbes, abdicaria de seu juízo privado totalmente, mas não é verdade, como o próprio Warrender observou:

O fato de a obrigação política, em Hobbes, depender, em última análise, de uma interpretação individual da lei natural, implica, também, a consequência de o súdito individual ter de decidir por si mesmo o ponto no qual termina toda a sua obrigação para com o soberano. A obrigação do súdito permanece enquanto o soberano tem o poder de protegê-lo; o súdito pode também resistir ao soberano quando a sua vida for diretamente ameaçada por ele. ${ }^{144}$

Deveras, Hobbes é bem claro em relação a esse ponto, inclusive no $D e$ cive: “Ninguém está obrigado ao que é impossível: portanto, quem se vê ameaçado pela morte, que é o maior dos males que possa afetar a natureza, ou por um ferimento ou ainda por danos físicos de qualquer espécie, e não é corajoso o bastante para suportá-los, não está obrigado a sofrê-los." ${ }^{145}$

No que concerne a Kant, ele define a legítima defesa do seguinte modo: "[...] ataque injusto [ungerechten] à minha vida, ao qual me antecipo tirando-lhe a sua (jus inculpatae tutelae), caso em que a recomendação da moderação (moderamen) não pertence sequer ao direito, e, sim, apenas à ética" ${ }^{146}$. Ele a admite no direito privado. Porém, para admiti-la no direito público implicaria ter que sustentar que o soberano pode ser injusto. Sobre esse ponto parece não haver coerência nas afirmações de Kant, pois, no texto Contra Hobbes ele sustenta que o soberano pode ser injusto, muito embora isso não dê qualquer direito ao súdito contra ele. ${ }^{147}$ Na Doutrina do direito ele sustenta que o monarca não pode ser injusto: "porque tudo o que ele [monarca] fez anteriormente na qualidade de um chefe tem de ser considerado como tendo ocorrido de forma exteriormente legítima, e ele próprio, considerado como fonte das leis, não pode ser injusto [nicht unrecht thun kann]."148

\footnotetext{
${ }^{143}$ OAKESHOTT, Michael. Hobbes on Civil Association. Indianapolis: Liberty Fund, 2000, p. 66. 144 WARRENDER, Howard. The Political Philosophy of Hobbes. Oxford: Oxford University Press, 1957, p. 149.

${ }^{145}$ HOBBES, Thomas. Do cidadão. [R. J. Ribeiro: Philosophical Rudiments Concerning Government and Society]. 2. ed., São Paulo: Martins Fontes, 1998 [1642], p. 107, cap. II, §18.

${ }^{146}$ KANT, Immanuel. A metafísica dos costumes. [Trad. J. Lamego]. Lisboa: Fundação Calouste Gulbenkian, 2005 [1797], p. 235-236 [MS, AA 06: 235-236].

147 “Segundo ele [Hobbes] (De Cive, cap. VII, g 14), o chefe de Estado de nenhum modo está ligado por contrato ao povo e não pode cometer injustiça [nicht Unrecht ] contra o cidadão (seja qual for a sua decisão a respeito deste). - Semelhante tese seria totalmente correcta se, por injustiça, se entende a lesão que reconhece ao lesado um direito de constrangimento relativamente àquele que comete a injustiça; mas, considerada na sua generalidade, a tese é terrível." [KANT, Immanuel. Sobre a expressão corrente: isso pode ser correcto na teoria, mas nada vale na prática. [Trad. Artur Morão]. Covilhã: Lusofia Press. [Disponível em: http://www. lusosofia.net/], p. 35 [TP, AA 08: 303-304]].

${ }_{148}$ KANT, Immanuel. A metafísica dos costumes. [Tr. J. Lamego]. Lisboa: Fundação Calouste Gulbenkian, 2005 [1797], p. 320-321 [RL, AA 06: 320-321].
} 
Por seu turno, ele define o direito no estado de necessidade como a defesa de uma "violência lícita contra aquele que não exerceu nenhuma [violência] contra mim." ${ }^{149}$ Kant não admite um direito no estado de necessidade nem no direito privado nem no direito público, isso em razão da prioridade do justo sobre o bem. ${ }^{150}$ Contudo, ele não deixa de tergiversar com tal conceito. Com efeito, no direito privado, em Contra Hobbes ${ }^{151}$ e na Doutrina do direito, ${ }^{152}$ ele admite a impunibilidade, embora não a inculpabilidade. Nesta última obra, ainda, ele sugere algum tipo de justificação para o destronamento de um monarca, a partir do direito de necessidade, como diz que poderia haver uma desculpa para o assassinato de um rei em razão da autoconservação. ${ }^{153}$ Por fim, ele parece

${ }^{149}$ KANT, Immanuel. A metafísica dos costumes. [Trad. J. Lamego]. Lisboa: Fundação Calouste Gulbenkian, 2005 [1797], p. 235-236 [MS, AA 06: 235-236].

150 "Conservar a minha vida é apenas um dever condicional (se tal puder ocorrer sem crime); mas é um dever incondicional não a tirar a outrem, que não me prejudica, e que nem sequer me põe em perigo de perder a minha." [KANT, Immanuel. Sobre a expressão corrente: isso pode ser correcto na teoria, mas nada vale na prática. [Trad. Artur Morão]. Covilhã: Lusofia Press, s/d [1793]. [http://www.lusosofia.net/], p. 31-32 [TP, AA 08: 300 nota]].

151 "Contudo, os professores de direito civil geral procedem de modo inteiramente consequente ao conceder autorização jurídica a este socorro na necessidade. Pois a autoridade não pode ligar nenhum castigo à interdição, porque tal pena deveria ser a morte. Mas seria uma lei absurda ameaçar com a morte alguém que, em circunstâncias perigosas, não se entregasse de bom grado à morte." [KANT, Immanuel. Sobre a expressão corrente: isso pode ser correcto na teoria, mas nada vale na prática. [Trad. Artur Morão]. Covilhã: Lusofia Press, s/d [1793]. [http://www.lusosofia.net/], p. 31-32 [TP, AA 08: 300 nota]].

152 “É claro que esta afirmação [direito no estado de necessidade] não deve ser entendida objetivamente, de acordo com aquilo que uma lei haveria de prescrever, mas apenas subjetivamente, como seria proferida a sentença perante o tribunal. Pois não pode haver uma lei penal que infligisse a morte àquele que, no naufrágio, encontrando-se com um outro em igual perigo de vida, empurrasse-o da tábua em que tinha se socorrido, a fim de se salvar a si mesmo. Pois a pena prevista pela lei não poderia certamente ser maior do que a da perda da vida do primeiro. Ora, uma tal lei penal não pode de maneira alguma ter o efeito intencionado, pois a ameaça com um mal que ainda é incerto (a morte pela sentença do juiz) não pode suplantar o medo diante do mal que é certo (a saber, o afogamento). Portanto o ato da autopreservação pela violência não deve ser julgado inculpável (inculpabile), mas apenas impunível (impunibile), e esta impunidade subjetiva é tomada pelos juristas, em uma confusão espantosa, por uma objetiva (legalidade). O ditado do direito de necessidade é: 'A necessidade não tem lei" (necessitas non habet legem)'; e mesmo assim não pode haver necessidade que tornasse legal [gesetzmäßig] o que é injusto [unrecht]." [KANT, Immanuel. A metafísica dos costumes. [Trad. J. Lamego]. Lisboa: Fundação Calouste Gulbenkian, 2005 [1797], p. 235-236 [MS, AA 06: 235-236]].

153 “Uma vez que o destronamento de um monarca pode ser pensado também como renúncia voluntária à coroa e abdicação de seu poder, com sua devolução ao povo, ou ainda como abandono do poder ocorrido sem atentado contra a pessoa suprema, com o que o poder voltaria ao estado privado, assim o crime do povo que o obteve por força tem ao menos a seu favor a desculpa do direito de necessidade (casus necessitatis), mas jamais o menor direito de puni-lo, enquanto chefe, por causa da administração anterior; porque tudo o que ele fez anteriormente na qualidade de um chefe tem de ser considerado como tendo ocorrido de forma exteriormente legítima, e ele próprio, considerado como fonte das leis, não pode ser injusto [nicht unrecht thun kann]. Mesmo o assassinato do monarca não é ainda o pior dos horrores de uma revolução política, pois então pode-se representar que ele se dê pelo povo por medo de que pudesse se reerguer, caso ficasse vivo, e fazer o povo sentir o merecido 
sugerir uma espécie de ameaça da natureza contra o soberano teimoso em reformar o Estado injusto. ${ }^{154}$

A resposta de Kant parece ser pior do que a de Hobbes. Nesse ponto se esperaria um Kant fundamentalmente diferente de Hobbes, mas ele é desoladoramente pior que Hobbes.

\section{Referências}

ALLISON, H. E. Kant's Theory of Freedom. New York: Cambridge University Press, 1990.

ALMEIDA, Guido Antônio de. Sobre o princípio e a lei universal do Direito em Kant. Kriterion. N. 114, 2006, p. 209-222.

BYRD, B. Sharon, HRUSCHKA, Joachim. Kant's 'Doctrine of Right': A Commentary. Cambridge: Cambridge University Press, 2010.

DARWALL, Stephen. Normativity and Projection in Hobbes's Leviathan. The Philosophical Review. V. 109, n. 3, 2000, p. 313-347.

DARWALL, Stephen. The British Moralists and the Internal 'Ought': 1640-1740. Cambridge: Cambridge University Press, 1995.

DUKE, George. Hobbes on Political Authority, Practical Reason and Truth. Law and Philosophy. V. 33, 2014, p. 605-627.

GREGOR, Mary J. Law of Freedom: A Study of Kant's Method of Applying the Categorical Imperative in the 'Methapysik der Sitten'. Oxford: Blackwell, 1963.

GREGOR, Mary J. Translator's Note on the text of The metaphysics of Morals. In KANT, Immanuel. Practical philosophy. [Transl. Mary Gregor]. [The Cambridge Edition of The Works of Immanuel Kant]. Cambridge: Cambridge University Press, 1996, p. 355-359.

HABERMAS, Jürgen. Direito e democracia: entre faticidade e validade. [v. I e II]. [Trad. F. B. Siebeneichler: Faktizität und Geltung: Beiträge zur Diskurstheorie des Rechts und des demokratischen Rechtsstaats]. Rio de Janeiro: Tempo Brasileiro, 1997.

HABERMAS, Jürgen. The Inclusion of the Other: Studies in Political Theory. Cambridge: MIT Press, 1998.

castigo, não pretendendo, pois, ser uma medida da justiça penal, mas meramente da autopreservação [Selbsterhaltung]." [KANT, Immanuel. A metafísica dos costumes. [Tr. J. Lamego]. Lisboa: Fundação Calouste Gulbenkian, 2005 [1797], p. 320-321 [RL, AA 06: 320-321]].

154 "A sabedoria política, no estado em que as coisas agora estão, converterá num dever a realização de reformas adequadas ao ideal do direito público: utilizará, porém, as revoluções, onde a natureza por si mesma [Natur von selbst] as suscita, não para desculpar uma opressão ainda maior, mas como apelo da natureza a instaurar, por meio de reformas profundas, uma constituição legal fundada nos princípios da liberdade, como a única constituição permanente." [KANT, Immanuel. A paz perpétua: um projeto filosófico. [Trad. Artur Morão]. Covilhã: Lusofia Press, 2008 [1795]. [http://www.lusosofia.net/], p. 37 [VAZeF, AA 08: 374 nota]]. Ora, o termo natureza poderia ser interpretada como sendo a princípio da autoconservação que opera no Estado de necessidade ou da legítima defesa, mas Kant aparentemente não declina o que ele entende por isso. 
HAMPTON, Jean. Hobbes and the Social Contract Tradition. Cambridge: Cambridge University Press, 1986.

HART, H. L. A. The Concept of Law. 2. ed., Oxford: Clarendon Press, 1994 [1961].

HERBERT, Gary B. Kant Contra Hobbes. Hobbes Studies. V. 17, n. 1, 2004, p. 3-27.

HOBBES, Thomas. Do cidadão. [R. J. Ribeiro: Philosophical Rudiments Concerning Government and Society]. 2. ed., São Paulo: Martins Fontes, 1998 [1642].

HOBBES, Thomas. Leviatã ou matéria, forma e poder de um estado eclesiástico e civil. [Trad. J. P. Monteiro e M.B.N. da Silva: Leviathan, or Matter, Form, and Power of a Commonwealth Ecclesiastical and Civil]. 2. ed., São Paulo: Abril Cultural, 1983 [1651].

HOBBES, Thomas. Leviathan, or Matter, Form, and Power of a Commonwealth Ecclesiastical and Civil. [Edited by C.B. Macpherson]. London: Penguin, 1968 [1651].

HOHFELD, Wesley Newcomb. Faulty Analysis in Easement and License Cases. The Yale Law Journal. V. 27, n. 1, 1917, p. 66-101.

HOHFELD, Wesley Newcomb. Some Fundamental Legal Conceptions as Applied in Judicial Reasoning. The Yale Law Journal. V. 23, n. 1, 1913, p. 16-59.

KANT, Immanuel. A metafísica dos costumes. [Trad. J. Lamego]. Lisboa: Fundação Calouste Gulbenkian, 2005 [1797].

KANT, Immanuel. A paz perpétua: um projeto filosófico. [Trad. Artur Morão]. Covilhã: Lusofia Press, 2008 [1795].

KANT, Immanuel. Fundamentação da metafísica dos costumes. [Trad. G. A. de Almeida: Grundlegung zur Metaphysik der Sitten]. São Paulo: Discurso Editorial/ Barcarolla, 2009 [1785].

KANT, Immanuel. Sobre a expressão corrente: isso pode ser correcto na teoria, mas nada vale na prática. [Trad. Artur Morão]. Covilhã: Lusofia Press, s/d [1793]. [http://www. lusosofia.net/].

KANT, Immanuel. Sobre um suposto direito de mentir. [Trad. Artur Morão]. Covilhã: Lusofia Press, s/d [1797].

KAVKA, Gregor. Right Reason and Natural Law in Hobbes's Ethics. The Monist. V. 66, 1983, p. 120-33.

KAVKA, Gregor. The Rationality of Rule-Following: Hobbes' Dispute with the Foole. Law and Philosophy. V. 14, 1995, p. 5-34.

LIMONGI, Maria Isabel. Direito e Poder: Hobbes e a dissolução do Estado. DoisPontos. V. 6, n. 3, 2009.

LLOYD, S. A. Morality in the Philosophy of Thomas Hobbes: Cases in the Law of Nature. Cambridge: Cambridge University Press, 2009.

MULHOLLAND, Leslie Arthur. Kant's System of Rights. New York: Columbia University Press, 1990.

NAGEL, Thomas. Hobbes's Concept of Obligation. Philosophical Review. V. 68, 1959.

OAKESHOTT, Michael. Hobbes on Civil Association. Indianapolis: Liberty Fund, 2000. 
PEACOCK, Mark. Obligation and Advantage in Hobbes' Leviathan. Canadian Journal of Philosophy. V. 40, n. 3, 2010.

PETTIT, Philip. Made with Words: Hobbes on Language, Mind, and Politics. Princeton and Oxford: Princeton University Press, 2008.

RACHELS, James, RACHELS, Stuart. The Elements of Moral Philosophy. 7. ed., New York: McGraw-Hill, 2012.

RAWLS, John. A Theory of Justice. [Revised Edition]. Oxford: Oxford University Press, 1999 [1971].

RAWLS, John. Lectures on the History of Political Philosophy. Cambridge, MA: Harvard University Press, 2007.

SCHMITT, Carl. El concepto de lo político. [Trad. Dénes Martos]. S/l: Katariche, s/d.

SCHMITT, Carl. El Leviathan en la teoría del estado de Tomas Hobbes. [Trad. F. J. Conde]. Granada: Comares, 2004 [1938].

SCHMITT, Carl. O conceito do político. [Trad. Álvaro L. M. Valls: Der Begriff des Politischen]. Petrópolis: Vozes, 1992 [1932].

SLOMP, Gabriella. Kant against Hobbes: Reasoning and Rhetoric. Journal of Moral Philosophy. V. 4, n. 2, 2007, p. 215-216.

STRAUSS, Leo. Notes on Carl Schmitt "The Concept of the Political". [Trans. by J. Harvey Lomax: Anmerkungen zu Carl Schmitt [1932]]. In SCHMITT, Carl The Concept of the Political. [Trans. George Schwab]. Chicago: University of Chicago Press, 2007.

TAYLOR, Alfred Edward. The Ethical Doctrine of Hobbes. Philosophy. N. 13, 1938, p. $406-424$.

VOLPATO DUTRA, Delamar José. Um homem não pode renunciar ao direito de resistir a quem o ataque pela força": a liberdade de desobedecer e o direito de resistir ao soberano segundo Hobbes. Síntese. V. 43, p. 5-38, 2016.

WALDRON, Jeremy. Kant's Legal Positivism. Harvard Law Review. N. 109, 19951996, p. 1535-1566.

WARRENDER, Howard. The Political Philosophy of Hobbes. Oxford: Oxford University Press, 1957.

WILLIAMS, Howard. Kant's Critique of Hobbes. Cardiff: University of Wales Press, 2003.

Endereço do Autor:

Praça Padre José de Anchieta, 21

88037-255 Florianópolis - SC

djvdutra@yahoo.com.br 